\title{
Historical forest biomass dynamics modelled with Landsat spectral trajectories
}

\author{
Cristina Gómez ${ }^{\mathrm{a}}$, Joanne C. White ${ }^{\mathrm{b}}$, Michael A. Wulder ${ }^{\mathrm{b}}$, Pablo Alejandro ${ }^{\mathrm{c}}$
}

a Sustainable Forest Management Research Institute, Universidad de Valladolid \& INIA, Palencia, 34004, Spain

${ }^{\mathrm{b}}$ Canadian Forest Service (Pacific Forestry Centre), Natural Resources Canada, Victoria, British Columbia, V8Z 1M5, Canada

${ }^{\mathrm{c}} 17$ Deveron Park, Huntly, AB54 8UZ, United Kingdom

Corresponding author: Cristina Gómez

E-mail: c.gomez@abdn.ac.uk

Keywords: remote sensing; time series; retrospective; above ground biomass; Landsat; wavelet transform, dynamic time warping, National Forest Inventory, Spain

\section{Pre-print of published version.}

\section{Reference:}

Gómez, C., White, J.C., Wulder, M.A., Alejandro, P. 2014. Historical forest biomass dynamics modelled with Landsat spectral trajectories. ISPRS Journal of Photogrammetry and Remote Sensing, 93, 14-28

\section{DOI.}

http://dx.doi.org/10.1016/j.isprsjprs.2014.03.008

\section{Disclaimer:}

The PDF document is a copy of the final version of this manuscript that was subsequently accepted by the journal for publication. The paper has been through peer review, but has not been subject to any additional copy-editing or journal specific formatting (so will look different from the final version of record, which may be accessed following the DOI above depending on your access situation) 


\begin{abstract}
Estimation of forest aboveground biomass (AGB) is informative of the role of forest ecosystems in local and global carbon budgets. There is a need to retrospectively estimate biomass in order to establish a historical baseline and enable reporting of change. In this research, we used temporal spectral trajectories to inform on forest successional development status in support of modelling and mapping of historic AGB for Mediterranean pines in central Spain. AGB generated with ground plot data from the Spanish National Forest Inventory (NFI), representing two collection periods (1990 and 2000), are linked with static and dynamic spectral data as captured by Landsat Thematic Mapper (TM) and Enhanced Thematic Mapper Plus (ETM+) sensors over a 25 year period (1984-2009). The importance of forest structural complexity on the relationship between AGB and spectral vegetation indices is revealed by the analysis of wavelet transforms. Two-dimensional (2D) wavelet transforms support the identification of spectral trajectory patterns of forest stands that in turn, are associated with traits of individual NFI plots, using a flexible algorithm sensitive to capturing time series similarity. Single-date spectral indices, temporal trajectories, and temporal derivatives associated with succession are used as input variables to non-parametric decision trees for modelling, estimation, and mapping of AGB and carbon sinks over the entire study area. Results indicate that patterns of change found in Normalized Difference Vegetation Index (NDVI) values are associated and relate well to classes of forest AGB. The Tasseled Cap Angle (TCA) index was found to be strongly related with forest density, although the related patterns of change had little relation with variability in historic AGB. By scaling biomass models through small ( 2.5 ha) spatial objects defined by spectral homogeneity, the AGB dynamics in the period 1990-2000 are mapped (70\% accuracy when validated with plot values of change), revealing an increase of 18\% in AGB irregularly distributed over $814 \mathrm{~km}^{2}$ of pines. The accumulation of C calculated in AGB was on average $0.65 \mathrm{t} \mathrm{ha}^{-1} \mathrm{y}^{-1}$, equivalent to a fixation of $2.38 \mathrm{tha}^{-1} \mathrm{y}^{-1}$ of carbon dioxide.
\end{abstract}

Keywords: remote sensing; time series; retrospective; above ground biomass; Landsat; wavelet transform, dynamic time warping, National Forest Inventory, Spain 


\section{Introduction}

Aboveground biomass (AGB) is a fundamental element of forest ecosystems. AGB is significant for its carbon storage capacity (Liski et al., 2000; Muukkonen and Heiskanen, 2007), and as a potential source of timber and production of bio-energy (FAO, 2003; Smeets and Faaij, 2007). Biomass amount per surface unit indicates the condition and productivity of a forest (FAO, 2010; Hall et al., 2006) and it is associated with ecological benefits related to biodiversity. Assessing forest AGB and related dynamics with spatially explicit detail is important for sustainable forest management (Herrero and Bravo, 2012; Tan et al., 2007), ecological applications (Barlow and Peres, 2004; Lewis et al., 2004), carbon accounting (Barredo et al., 2012; Houghton, 2005), for providing information in support of carbon markets (Goetz et al., 2009; Wang et al., 2009), and for reporting commitments (Andersson et al., 2009; Kurz and Apps, 2006).

Remote sensing has become the primary data source for large area biomass estimation (Lu, 2006), providing spatial detail to capture ground variability (Wulder et al., 2008), and temporal repetition to account for change (Powell et al., 2010). As summarized by Kangas and Maltamo (2006), national forest inventories (NFI) supply precise information based on plot measurements (e.g. Finland, USA), frequently supported by aerial photography or satellite data (e.g. UK, Canada) that can be scaled and extended to unmeasured areas through direct modelling with passive or active remotely sensed data (Baccini et al., 2004; Blackard et al., 2008). Estimation and monitoring of AGB with remotely sensed data sources can be fast and relatively low cost, providing information for remote and inaccessible areas (Bortolot and Wynne, 2005). While error estimates are ultimately linked to the quality of the reference data (Baccini et al., 2007), improved processing algorithms and techniques for data analysis can enhance the accuracy of AGB estimates from remotely sensed data sources ( $\mathrm{Lu}, 2006)$. The radiometric saturation of optical sensors at high levels of biomass is well known (Gemmell, 1995; Lu, 2005; Turner et al., 1999). Saturation is also a problem for radar instruments (Englhart et al., 2011; Mitchard et al., 2009), with the degree of saturation dependent on wavelength, polarization, and vegetation structure ( $\mathrm{Lu}, 2006)$. Airborne and spaceborne LiDAR can provide an important alternative source of forest structural information (Duncanson et al., 2010; Kwak et al., 2010; Næsset and Gobakken, 2008), and combinations of data from multiple sensors provide robust options for estimation of forest biomass (Sun et al., 2011; Yu et al., 2010).

Retrospective estimation of AGB to establish a historical baseline and enable change reporting is feasible with archival data, where the Landsat program provides the longest and most consistent repository of imagery, going back to 1972 (Wulder et al., 2012). The Landsat archive is also the only realistic source of 
data for mapping at the level of detail required by international treaties (e.g. Kyoto Protocol). Methods to map historical forest attributes may apply date invariant relationships (Healey et al., 2006; Powell et al., 2010) to past data using static measures (i.e. spectral predictors obtained at a given time). The relationship between contemporary spectral and reference data is extended to other dates of interest, relying on a robust process of relative radiometric normalization of imagery, for estimation of change. Incorporation of dynamic variables, that is, predictors combining data captured at various dates, for modelling AGB and its dynamics remains unexplored. In this work we estimate and map historical AGB in central Spain using temporally irregular trajectories of spectral indices from Landsat records, supported with information derived from NFI measurements.

Our goal is to estimate and map historical AGB (at specified dates in time), as well as a decade of change in AGB, by combining the precision of field measures from a network of NFI plots with the wall-to-wall spatial coverage provided by remotely sensed data. We first explore the relationship between live AGB derived from NFI ground plot measurements and vegetation spectral indices derived from Landsat data. Second, we model past AGB with historical spectral data, including single-date data and multi-temporal trajectories, providing a baseline for comparison with more recent estimations. Lastly, we map historical AGB at two dates coincident with NFI rotations (1990 and 2000) and evaluate the distribution of change in view of the uncertainties associated with the process of modelling and mapping.

\subsection{Background}

Estimation of forest biomass with optical remotely sensed data is based on the assumption of a strong statistical relationship between AGB and the spectral response as captured by the sensor (Lu, 2006). Providing there are an adequate number of quality ground samples, direct modelling of AGB relies on the choice of a set of appropriate predictor variables and the development of suitable estimation models (Lu et al., 2012). The most frequently attempted model types are regression (González-Alonso et al., 2006; Rahman et al., 2005), imputation (Chirici et al., 2008; Fazakas et al., 1999), neural networks (Foody et al., 2001; Jin and Liu, 1997) and decision trees (Blackard et al., 2008; Mutanga et al., 2012). The adequacy of a model depends on data availability, desired precision, transparency, and site-specific characteristics (Labrecque et al., 2006). Amongst the suite of possible predictor variables of AGB, the calibrated reflectance of visible and near-infrared wavelengths without further processing is sometimes used, although vegetation indices (i.e. combinations of two or more spectral bands) are recommended for the capacity to reduce noise effects associated with canopy shadows (Gemmell, 1999), which can be relevant in sites of complex vegetation structure (Lu et al., 2004). 
Empirical relationships between forest AGB and spectral properties-as captured by optical sensorshave been intensively explored in a broad range of biomes and are site specific (e.g. Foody et al., 2003; Gemmell, 1998). Uncertainties in this empirical relationship may arise from sensor limitations (e.g. viewing angle, radiometric resolution), atmospheric effects (e.g. haze, cloud), vegetation phenology, and topographic characteristics (Gemmell, 1998), but also from intrinsic forest structure and variability (Gemmell, 1995; Lu et al., 2005). In Mediterranean forests, typically characterized by rugged locations and structural heterogeneity (Salvador and Pons, 1998), the relationship between AGB and spectral response has proven difficult to characterize (e.g. Maselli et al., 2005; Vázquez de la Cueva, 2008).

\subsection{Incorporation of temporal information into modelling of forest attributes}

The majority of direct models incorporate data captured at a single point in time, which ideally is as close as possible to the timing of reference data collection on the ground. Multi-seasonal imagery has been shown to improve the accuracy of forest biomass estimation (Gasparri et al., 2010; Lefsky et al., 2001). Furthermore, the benefits of multi-temporal data for estimation of successional processes (Song et al., 2002; Song et al., 2007) and forest structure (Gemmell et al., 2001), both of which are intimately linked to AGB, have been acknowledged, with multiple images analyzed independently (Foody et al., 1996) or linked in a temporal trajectory (Liu et al., 2008).

Open access data policies facilitating the use of image time series (Wulder et al., 2012) have prompted the emergence of new approaches to extract information from spatially coincident multi-date imagery (Table 1). Polynomial characterization of spectral curves (Goodwin et al., 2010) or identification of distinctive trajectory segments (Kennedy et al., 2010) are alternative options to make use of the inherent temporal information of a series of calibrated data for interpretation of ecological processes. We explore here an option to directly incorporate temporal information in predictor variables for estimation of AGB. The empirical models linking AGB measurements with Landsat spectral data facilitate mapping of forest biomass and change. 
Table 1. Forest studies capitalizing on information from Landsat imagery spectral trajectories.

\begin{tabular}{|c|c|c|c|}
\hline \multirow{2}{*}{ Study } & \multirow{2}{*}{ Ecosystem/ Location } & \multicolumn{2}{|l|}{ Goal } \\
\hline & & Approach & Spectral variable \\
\hline \multirow[b]{2}{*}{ Liu et al., 2008} & \multirow{2}{*}{$\begin{array}{l}\text { Coniferous / } \\
\text { Oregon (USA) }\end{array}$} & \multicolumn{2}{|c|}{ Prediction of forest successional stages } \\
\hline & & $\begin{array}{l}\text { Modelling with progressive multi- } \\
\text { date predictors }\end{array}$ & TCB,TCG,TCW \\
\hline \multirow{2}{*}{ Huang et al., 2009} & \multirow{2}{*}{$\begin{array}{l}\text { Various National } \\
\text { Forests / } \\
\text { (USA) }\end{array}$} & \multicolumn{2}{|c|}{$\begin{array}{l}\text { Validation of VCT performance in detection of forest change } \\
\text { dynamics }\end{array}$} \\
\hline & & $\begin{array}{l}\text { Interpretation of IFZ temporal } \\
\text { profiles }\end{array}$ & $\begin{array}{l}\text { IFZ (Red, SWIR1, } \\
\text { SWIR2) }\end{array}$ \\
\hline \multirow{2}{*}{ Goodwin et al., 2010} & \multirow{2}{*}{$\begin{array}{l}\text { Coniferous / } \\
\text { British Columbia } \\
\text { (Canada) }\end{array}$} & \multicolumn{2}{|c|}{ Characterization of mountain pine beetle infestation } \\
\hline & & Polynomial curve fitting model & NDMI \\
\hline \multirow{2}{*}{ Kennedy et al., 2010} & \multirow{2}{*}{$\begin{array}{l}\text { Coniferous and } \\
\text { broadleaved / } \\
\text { Oregon and } \\
\text { Washington (USA) }\end{array}$} & \multicolumn{2}{|c|}{$\begin{array}{l}\text { Description of successional processes: disturbance and } \\
\text { recovery }\end{array}$} \\
\hline & & $\begin{array}{l}\text { Temporal segmentation and } \\
\text { interpretation of segments }\end{array}$ & NDVI, NBR, TCW \\
\hline \multirow[b]{2}{*}{ Powell et al., 2010} & \multirow{2}{*}{$\begin{array}{l}\text { Coniferous and } \\
\text { mixed / } \\
\text { Arizona and } \\
\text { Minnesota (USA) }\end{array}$} & \multicolumn{2}{|l|}{ Assessment of AGB over two decades } \\
\hline & & Trajectory of modelled AGB & $\begin{array}{l}\text { TCA, TCB, TCG, } \\
\text { TCW, DI, } \\
\text { Reflectances }\end{array}$ \\
\hline \multirow[b]{2}{*}{ Gómez et al., 2012} & \multirow[b]{2}{*}{$\begin{array}{l}\text { Mediterranean pines / } \\
\text { (Spain) }\end{array}$} & \multicolumn{2}{|c|}{ Assessment of 25 years of carbon fluxes } \\
\hline & & $\begin{array}{l}\text { Temporal derivative of spectral } \\
\text { trajectory with interpretation of } \\
\text { state and process }\end{array}$ & TCA \\
\hline \multirow[b]{2}{*}{ Pflugmacher et al., 2012} & \multirow{2}{*}{$\begin{array}{l}\text { Mixed-conifer forest / } \\
\text { Oregon (USA) }\end{array}$} & \multicolumn{2}{|c|}{$\begin{array}{l}\text { Estimation of current structural parameters (live and dead } \\
\text { biomass) }\end{array}$} \\
\hline & & $\begin{array}{l}\text { Model current parameters with } \\
\text { disturbance and recovery features } \\
\text { derived from spectral trajectories }\end{array}$ & TCA, TCB,TCG,TCW \\
\hline \multirow[b]{2}{*}{ Zhu et al., 2012} & \multirow{2}{*}{$\begin{array}{l}\text { Evergreen forest / } \\
\text { Georgia and } \\
\text { California (USA) }\end{array}$} & \multicolumn{2}{|l|}{ Monitoring of forest disturbance } \\
\hline & & $\begin{array}{l}\text { Dense time series models } \\
\text { phenology with trigonometric } \\
\text { functions for detection of change }\end{array}$ & DI \\
\hline
\end{tabular}

DI: Disturbance Index; IFZ: Integrated Forest Z-score; NDMI: Normalized Difference Moisture Index; NDVI: Normalized Difference Vegetation Index; TCA: Tasseled Cap Angle; TCB: Tasseled Cap Brightness; TCG: Tasseled Cap Greenness; TCW: Tasseled Cap Wetness.

\subsection{Wavelet transforms in remote sensing and forestry applications}

Wavelet transforms have been used in the remote sensing community for image blending (GarguetDuport et al., 1996; Zhou et al., 1998), for detection of haze (Du et al., 2002), spectral unmixing of hyperspectral data (Li, 2004), post-classification change detection (Raja, 2013), and feature extraction (Fukuda and Hirosawa, 1999; Niedermeier et al., 2000; Simhadri et al., 1998). In relation to vegetation dynamics, Sakamoto et al. (2005) developed a method for detection of crop phenology incorporating wavelet filters. Percival et al. (2004) proposed the usefulness of the multi-resolution analysis (MRA) 
applied to vegetation time series, with which Martínez and Gilabert (2009) identified seasonal and long term trend changes of various land covers in Spain. Freitas and Shimabukuro (2008) applied MRA to spectral fractions of MODIS bands for analysis of land cover change in Brazil, identifying the location and time of disturbance events.

As a tool for analysis of data, wavelet transform techniques facilitate the characterization of nonstationary processes (Meyers et al., 1993), that is, processes of change dependent on the scale of variation. The most distinctive property of wavelet transforms is the capacity to provide local information of the target series $\mathrm{F}(\mathrm{x})$ and at a range of selected scales (Lindsay et al., 1996). This property derives directly from the wavelet definition as a function that oscillates around zero, and that is localized in a finite width interval (Meyers et al., 1993). Basically, a wavelet transform decomposes the original series $\mathrm{F}(\mathrm{x})$ into a set of functions by convolving $\mathrm{F}(\mathrm{x})$ with a family of wavelets, which are derived by scaling and translation of a mother or basis function $\mathrm{G}(\mathrm{x})$. As result of the wavelet transform a number of functions are produced, one approximation $\left(\mathrm{A}_{\mathrm{i}}\right)$ and one detail $\left(\mathrm{D}_{\mathrm{i}}\right)$ function per scale or level. Another interesting property of the wavelet transform is that the original series can always be reconstructed from its decomposed elements: at any level of decomposition (i) the original series $\mathrm{F}(\mathrm{x})$ equals that level approximation $A_{i}$ plus the sum of all lower level details $\left(\Sigma D_{j}\right)(j=1 \ldots i-1)$. For the sake of interpretation, approximation functions inform trends of change whilst detail functions account for high frequency related with noise (Percival et al., 2004) and are associated with changes in averages at each given scale. A measure of variance or energy associated with each function helps identify which are the most relevant levels of the wavelet transform decomposition (Lindsay et al., 1996). Wavelet transforms are used in this work with a double purpose: exploratory analysis of the relationship between spectral indices and plot measured AGB, and smoothing of a system of data for derivation of dynamic spectral variables.

\section{Methods}

\subsection{Overview}

The relationship between AGB and spectral properties at the plot level was explored in a forest ecosystem of Mediterranean pines. Vegetation indices suitable for modelling AGB were identified. Dynamic spectral variables associated with forest successional development were defined through wavelet transformations of a data system formed by a set of spatially coincident field measures and corresponding calibrated spectral data captured over 25 years. The domain of the dynamic variables was identified as a number of modelled trajectories. To test the significance of the dynamic spectral variables in predicting AGB, a binary rule-based approach was applied to ground plots characterized by dynamic, as well as static variables, in order to identify the most relevant predictors. Cross-validation was used to determine the 
best binary model for AGB in 1990 and 2000; the best binary models were then applied to small spectrally homogenous ground units for mapping AGB and carbon dynamics over the entire study area. The resulting map of AGB change was validated with plot values of biomass change. Figure 1 provides an overview of the main methods applied in this work.

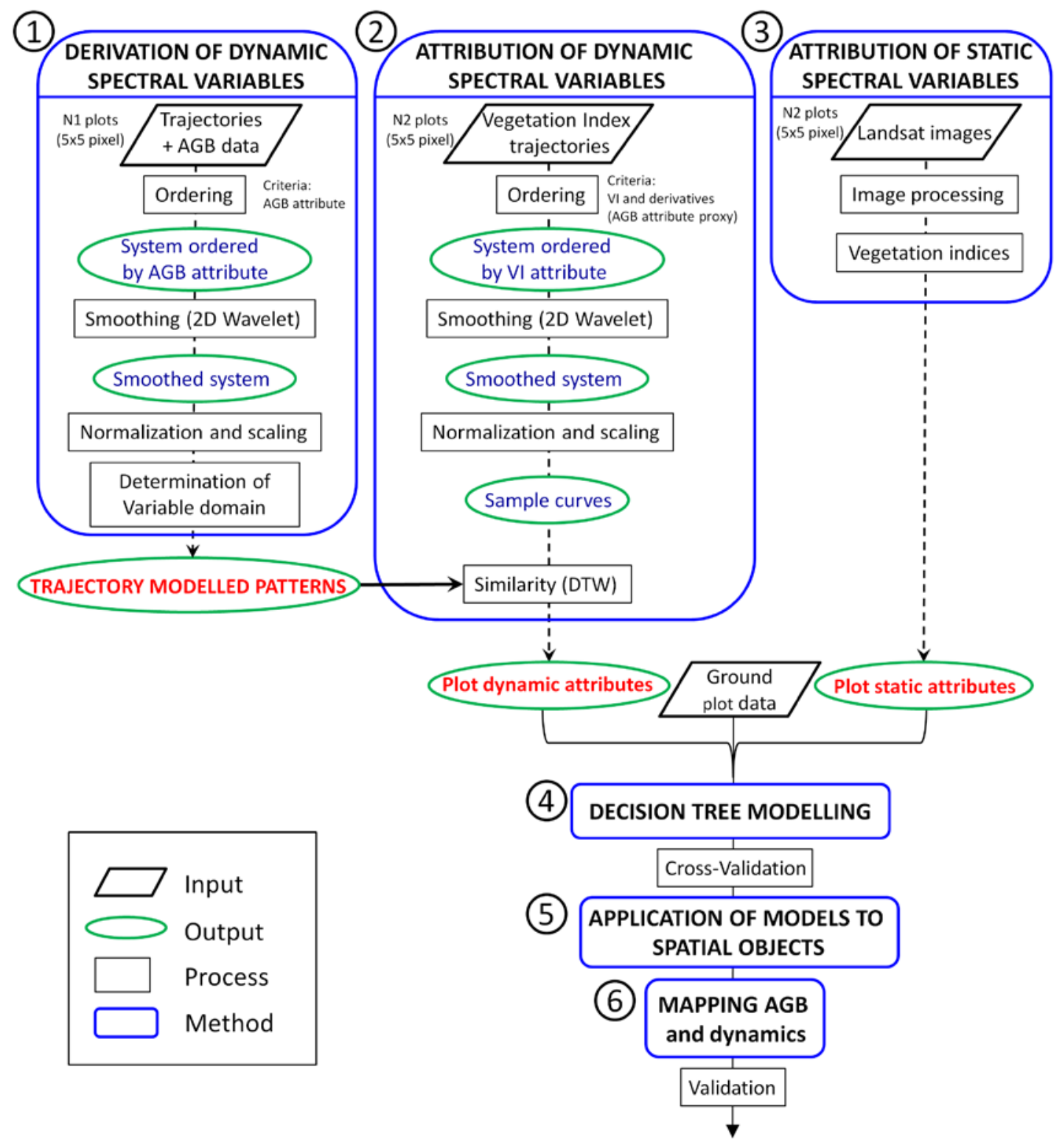

Figure 1. Schematic representation of main methods followed in this study. Dynamic spectral variables are defined with a flow process based on $2 D$ wavelet transforms, and the domain of each variable is identified as a number of modelled trajectories. Sample plots of unknown AGB are attributed dynamic variables by maximum similarity to trajectory models. Statistical models of AGB at the plot level are derived with a binary-rule approach based on dynamic and static spectral variables. These models are applied to the entire area to map estimated AGB dynamics between 1990 and 2000. 


\subsection{Study area}

The study area is centred at latitude $40^{\circ} 37^{\prime} 56^{\prime \prime} \mathrm{N}$ and longitude $-4^{\circ} 6^{\prime} 47^{\prime \prime} \mathrm{E}$, in the Central Range of Spain, and occupies part of the Ávila, Segovia, Madrid, Guadalajara and Toledo provinces (Figure 2). It is a pine ecosystem with dominant tree species Pinus sylvestris L., Pinus pinaster Ait., and Pinus nigra Arn. Forests extend to elevations of 2000 m, beyond which shrubs (Cytisus sp., Genista sp., Erica sp., Echinospartum sp.) are the prevalent vegetation (Rivas-Martínez, 1963). Some of these Mediterranean pines have traditionally been managed for production of resin and timber, recreation, and protection, with the last two objectives having increasing importance. A range of structural conditions (e.g. mono-specific and even aged, multi-species, multi-layer) have resulted from the various management practices that have been applied, including the non-management option (e.g. multi-aged, multi-story). Stand age classes are typically defined as 20-year intervals for the species in the entire area (Serrada, 2008). Silvicultural practices include pruning and thinning, with timber extraction implemented over time by progressive cuts of low intensity.

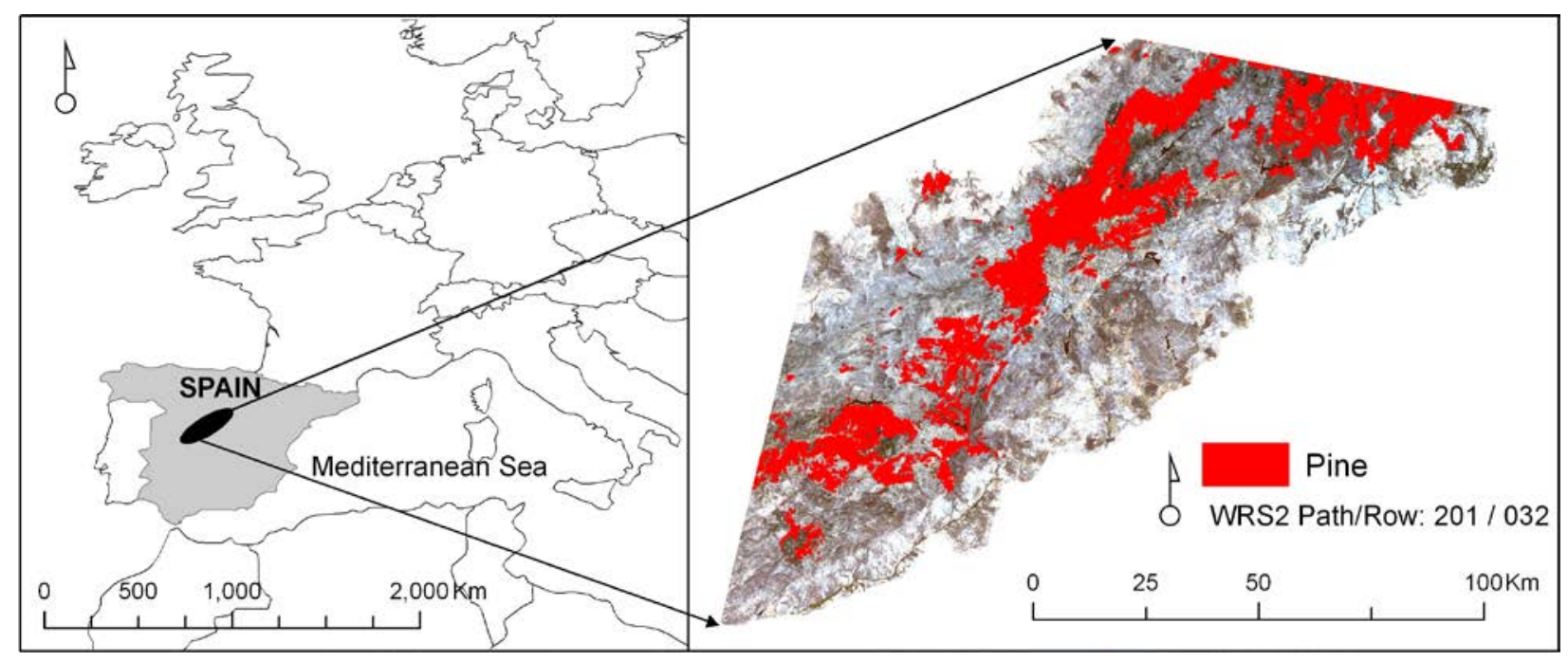

Figure 2. Location of the study area in the Central Range of Spain. It is a Mediterranean ecosystem that has been permanently covered with pine forests during period 1984-2009.

\subsection{Ground plot data and derived ground plot attributes}

Two rounds of the Spanish National Forest Inventory data (NFI2 ca. 1990 and NFI3 ca. 2000) (Bravo et al., 2002), including per tree measures of diameter at breast height (D), total height (H), and per plot number of trees $(\mathrm{N})$, were used for calculation of biomass in 605 plots spread over an area permanently forested with pines over the period 1984-2009 (Gómez et al., 2012). In this area NFI plots were de facto measured during the 1992-1994 and 2000-2004 campaigns of the NFI2 and NFI3 respectively. Live 
AGB was calculated with the species specific allometric equations of Montero et al. (2005) and RuizPeinado et al. (2011) for all trees with $\mathrm{D} \geq 7.5 \mathrm{~cm}$. These equations can determine the dry biomass fraction of stem, roots, and branches of various dimensions; however, we did not consider the root portion in our analysis, and focused on the AGB. Absolute and relative change of AGB between the rounds of NFI was calculated (Table 2). NFI2 intra- plot structural complexity was evaluated as in Gómez et al. (2011a) calculating the median absolute deviation (MAD) of measured $\mathrm{D}\left(\mathrm{D}_{\mathrm{MAD}}\right)$ and $\mathrm{H}\left(\mathrm{H}_{\mathrm{MAD}}\right)$ in each plot: increasing values of the MAD indicate higher structural complexity, and a zero MAD value is possible but unlikely to occur if all trees in a plot have exactly the same dimension. Thirty two plots subject to complete resource extraction between the two NFI rounds were disqualified in support of our assumption of near to natural successional conditions, leaving 573 plots for further analysis.

Table 2. Statistics of the attributes related to biomass $\left(t h^{-1}\right)$ and structural complexity evaluated at NFI plots.

\begin{tabular}{|c|c|c|c|c|c|c|}
\hline Attribute type & $\begin{array}{c}\text { Plot } \\
\text { Attribute }\end{array}$ & Description & Mean & Std. dev. & Min. & Max. \\
\hline \multirow{5}{*}{ Biomass } & $\mathrm{AGB}_{1990}$ & Above ground biomass NFI2 (1990) & 93.29 & 67.09 & 1.45 & 352.08 \\
\hline & $\mathrm{AGB}_{2000}$ & Above ground biomass NFI3 (2000) & 109.36 & 68.99 & 0 & 398.90 \\
\hline & $\overline{\Delta \mathrm{AGB}}$ & Increment of AGB between NFI2 and NFI3 & 14.80 & 50.07 & -236.86 & 242.38 \\
\hline & $\operatorname{Rel}_{1990}$ & Increment of AGB relative to $\mathrm{AGB}_{1990}$ & 0.79 & 2.55 & -1 & 28.41 \\
\hline & $\overline{\operatorname{Rel}_{2000}}$ & Increment of AGB relative to $\mathrm{AGB}_{2000}$ & -0.03 & 1.33 & -17.00 & 0.96 \\
\hline \multirow{2}{*}{$\begin{array}{l}\text { Structural } \\
\text { complexity }\end{array}$} & $\mathrm{D}_{\mathrm{MAD}}$ & Median absolute deviation of D (1990) & 4.59 & 3.93 & 0 & 8.00 \\
\hline & $\mathrm{H}_{\mathrm{MAD}}$ & Median absolute deviation of H (1990) & 1.81 & 1.18 & 0 & 24.35 \\
\hline
\end{tabular}

\subsection{Landsat data and processing}

Eight Landsat TM and ETM+ images (path/row: 201/32) spanning 25 years (1984-2009) (Table 3) were processed following standard procedures that include atmospheric correction of a reference image (date 2000) with the COST method (Chávez, 1988), relative radiometric normalization of the whole series with IR-MAD (Canty et al., 2004), ortho-correction with a $30 \mathrm{~m}$ digital elevation model, and geometric coregistration (RMSE < 0.5 pixel), following a processing flow recommended for detection of vegetation dynamics (Vicente-Serrano et al., 2008). A set of near anniversary images at an advanced date in the growing season was selected to minimize phenological fluctuations. Spectral vegetation indices related with forest biomass and structure such as the Normalized Difference Vegetation Index (NDVI) (Dong et al., 2003; Piao et al., 2005), the Tasseled Cap Angle (TCA) (Gómez et al., 2012; Powell et al., 2010; Pflugmacher et al., 2012) and the Tasseled Cap Distance (TCD) (Duane et al., 2010; Powell et al., 2010) 
were derived from normalized Landsat reflectances. The temporal trajectory, namely the sequence of spectral values obtained from consecutive images of these spectral indices at averaged $5 \times 5$ pixel windows centred at the 573 NFI plots were identified and saved for analysis.

Table 3. Landsat imagery used in the study. Reference image for relative radiometric normalization (22/08/2000) is highlighted.

\begin{tabular}{ccc}
\hline Landsat / Sensor & dd/mm/yyyy & Sun elev. $\left(^{\mathbf{0}}\right.$ ) \\
\hline 5 / TM & $18 / 08 / 1984$ & 52.89 \\
\hline 5 / TM & $11 / 08 / 1987$ & 54.11 \\
\hline 4 / TM & $11 / 08 / 1990$ & 54.38 \\
\hline 4 / TM & $14 / 08 / 1991$ & 51.68 \\
\hline 7 / ETM+ & $22 / 08 / 2000$ & 54.87 \\
\hline 5 / TM & $07 / 08 / 2003$ & 56.50 \\
\hline 5 / TM & $25 / 08 / 2004$ & 53.15 \\
\hline 5 / TM & $23 / 08 / 2009$ & 54.48 \\
\hline
\end{tabular}

\subsection{Relationships between ground plot estimates of AGB and spectral vegetation indices}

To explore the relationship between plot AGB and vegetation spectral indices (NDVI, TCA, and TCD), temporal spectral trajectories were compiled into a block of trajectories ordered by increasing value of AGB (Figure 3). For instance, the NDVI $_{\text {block }}$ consists of 573 NDVI trajectories (one per $5 \times 5$ pixel window-plot), and similarly the TCA block $_{\text {and the TCD }}$ block consist of 573 TCA and 573 TCD trajectories respectively. Each data system provides information that can be interpreted in the temporal or the biomass directions. Examined in the AGB direction, the spectral series represent at each date (1984 to 2009) a function of increasing AGB. At dates corresponding with the NFI2 (1990) and the NFI3 (2000), the values of the biomass function are known (calculated from field measures).

The spectral blocks of original trajectories (before wavelet smoothing) are characterized by high variability in the temporal and biomass directions, derived from sensor and environmental factors. Smoothing the system of spectral trajectories with a one-dimensional wavelet transform in the biomass direction reveals the essential underlying relationship AGB-spectral index. We run a discrete wavelet transformation through a family of Meyer wavelets, specifically adapted for sampled series (Daubechies, 1992; Lindsay et al., 1996) followed by multi-resolution analysis for interpretation. The multilevel wavelet transformation smoothes the spectral system by isolating high frequency noise from the lower frequency basic signal (Figure 3). The level of decomposition necessary to isolate base information is related to the number and frequency of samples, and it is linked to the family of wavelets used. We run an 
eight level decomposition and found level six, with highest measure of variance, the most useful for description and interpretation. Running the wavelet transform simultaneously over the complete spectral block (1984-2009) rather than a single date function provides information of local (AGB) and temporal discontinuities, irregularities or exceptions, as well as an easy means to visually interpret information (Freitas and Shimabukuro, 2008).

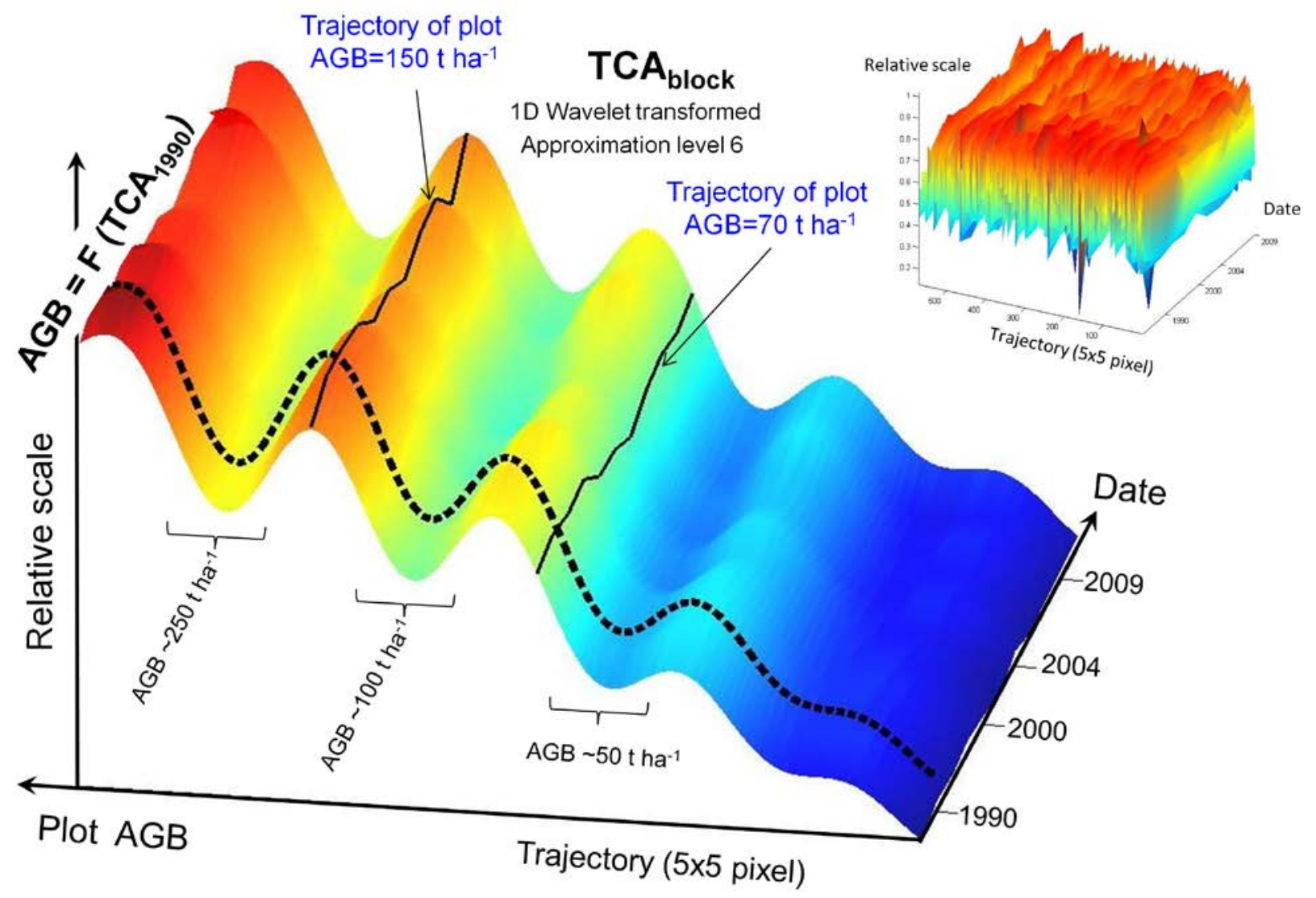

Figure 3. $T C A_{\text {block }}$ for exploration of the relationship between the spectral index and plot AGB. The level 6 approximation of the smoothed system is represented. A positive relation AGB $=F(T C A)$ is evident although broken at intervals by the influence of endogenous (structure) and exogenous (topography, sensor) factors, conferring the system its wavy aspect.

The influence of local structural complexity on the relationship AGB-spectral index was explored with blocks of spectral trajectories previously modified by standardized values of MAD (plot $\mathrm{D}_{\text {MAD }}$ and $\mathrm{H}_{\mathrm{MAD}}$ ). Constant structural complexity over the period 1984-2009 was assumed for each plot; therefore only one value of $\mathrm{D}_{\mathrm{MAD}}$ and $\mathrm{H}_{\mathrm{MAD}}$ was calculated for each plot (with NFI2 data) and applied to the entire trajectory. The blocks' sampling interval is neither regular in the temporal nor in the biomass direction, and it enables inference of qualitative information but has limited capacity to infer quantitative relations. For this reason, and with the aim to identify AGB categories as are routinely used in regional forest 
management, that could be unequivocally related with vegetation indices, we undertook a second exploratory analysis that included a sub-sample of 182 plots regularly distributed every $\sim 1.7 \mathrm{t} \mathrm{ha}^{-1}$ over the range $1-310 \mathrm{tha}^{-1}$.

In the following sections we describe the process followed for modelling and mapping historical AGB and AGB dynamics during period 1990-2000. Figure 1 provides a summary of all stages to aid the reader in following the methods presented.

\subsection{Derivation of dynamic spectral variables and trajectory models}

The temporal series of spectral values depict rich and complex information that typically require specifically developed methods to expose. In order to derive an assortment of dynamic variables, each relating inherent temporal dimensionality, original trajectories and temporal derivatives (Gómez et al., 2011b) of a set of plots measured on the ground were considered (N1=573). The sparse and irregular character of the series of spectral data available, with 8 samples in a 25 year interval (Table 3) required regularization by linear interpolation for completeness and easiness of interpretation. The state (original trajectory) and process (temporal derivative trajectory) of $\mathrm{NDVI}_{\text {block }}$ (573 NDVI trajectories) and TCA $\mathrm{block}_{\mathrm{b}}$ (573 TCA trajectories) were independently organized (ordered) by a biomass attribute (AGB 1990, AGB $_{2000}$, $\triangle \mathrm{AGB}, \mathrm{Rel}_{1990}$, or $\mathrm{Rel}_{2000}$ ) and subject to a 2D wavelet smoothing filter. In this way, 16 ordered and smoothed data systems (M1 to M16) were considered (Table 4) and identified as dynamic variables (Figure 1, box 1). For instance, M11-M16 describe the successional path of these forests, while M1-M10 describe the changing pace, as represented by NDVI and TCA values over time, always relative to this particular area. The wavelet transform scale was adjusted in each direction, with six levels in the biomass direction and two levels in the temporal direction. For each system (Table 4) the domain of a dynamic variable is defined by semi-automatic identification of six to eight distinctive curve patterns (Figure 4, bottom). The independence of the smoothed systems and associated dynamic variables is assured by the individuality of the ordering criteria (Figure 4, top).

The dynamic variables can be grouped as state or process variables (Table 4). State variables are made up by the temporal spectral trajectory, while process variables are associated with the temporal derivatives of those trajectories (Gómez et al., 2011b). Ideally, if endogenous factors (e.g. structural complexity) and exogenous factors (e.g. topography, sensor limitations) were controlled or suppressed, state variables could describe the evolution of forest biophysical parameters related with spectral indices, and process variables would represent the rate at which those processes of change occurred. In reality, only approximations can be interpreted, as no single state or process variable is capable of completely explaining the biophysical development of forests. 

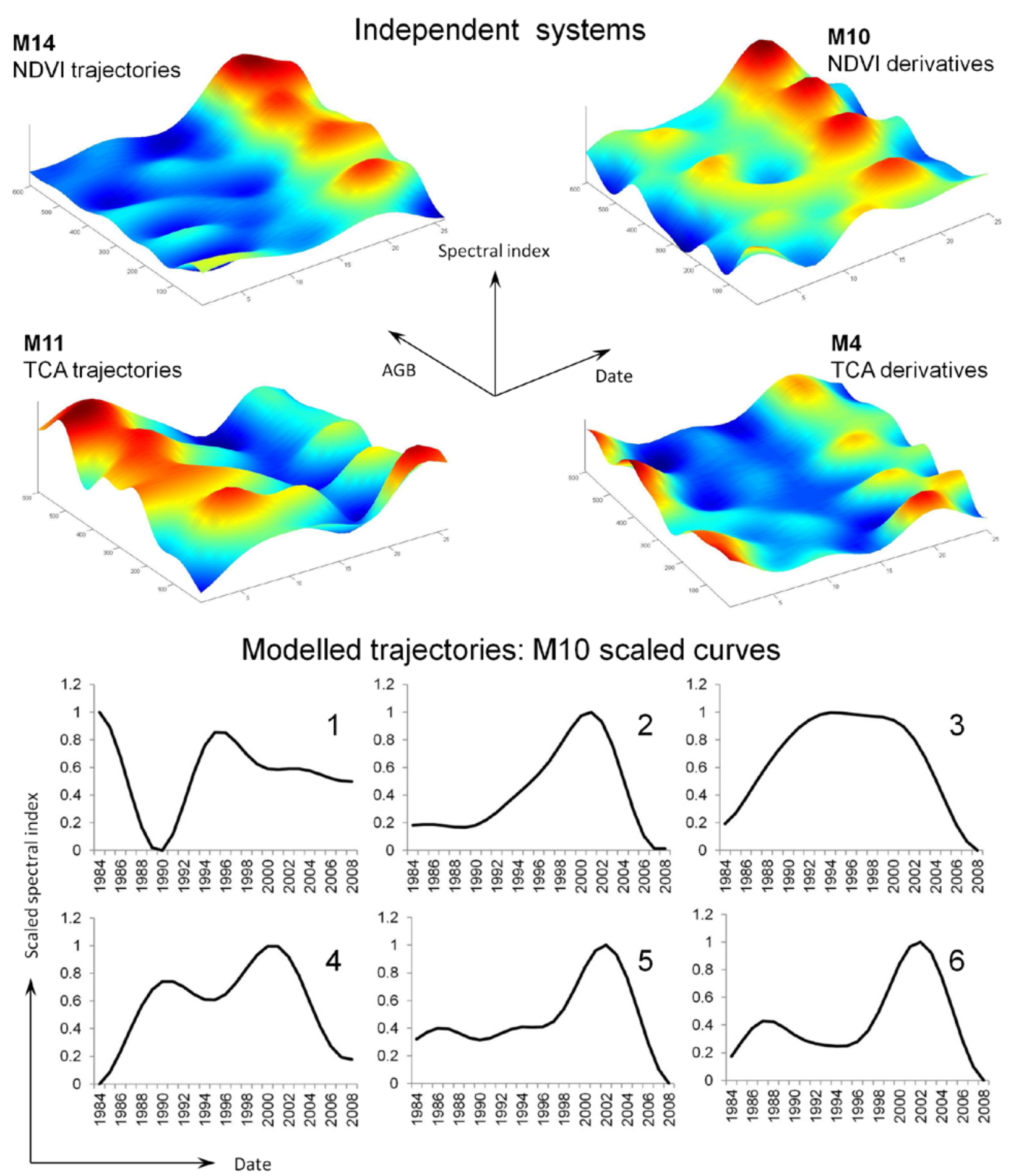

Figure 4. Illustration of stages in the derivation of dynamic spectral variables. Top: examples of independent and smoothed ( $2 D$ wavelet) ordered data systems: M14 (NDVI state trajectories ordered by AGB1990); M10 (NDVI process trajectories ordered by AGB2000); M11 (TCA state trajectories ordered by AGB1990); M4 (TCA process trajectories ordered by AGB1990). Bottom: examples of modelled NDVI process patterns obtained from the data system M10 (NDVI process trajectories ordered by AGB2000). 
As an example, M5 (Table 4) is a process variable originated by the system of TCA derivative trajectories ordered by $\mathrm{AGB}_{2000}$ and smoothed in two directions (time and biomass). M5 domain consists of 8 patterns for period 1984-2009: in this area the TCA rate of change at the plot level follows one of 8 patterns, each one expected to be related to a different amount of AGB. To enable later comparison, model curves were normalized and scaled between zero and one.

The effectiveness of spectral trajectories as predictor variables is likely to be related to duration and starting position, which in turn might be limited by data availability. Acknowledging the importance of these features we tested the performance of two versions of each variable. Hence, in addition to the complete 25-year (1984-2009) spectral trajectory available, a 15-year (1990-2004) version, spanning the time lapse between NFI2 and NFI3 measurements, was considered. The initial point of the 15-year variables is coincident with NFI2 ground measurements.

\subsection{Attribution of dynamic spectral variables to unmeasured locations}

Intending to recognize the nature of the spectral trajectories with highest capacity to describe AGB, dynamic variables related with successional processes have been created in a process with controlled AGB parameters. The predictive capacity of these variables has to be tested over locations of unknown AGB. In order to assign values of each dynamic variable domain to any ground location of unmeasured AGB, its corresponding temporal spectral trajectory is included into a system of spectral trajectories. The system needs to be subject to mathematical transformations similar to the models: ordering and 2D wavelet smoothing (Figure 1, box 2). In this case, as AGB parameters are unknown, spectral indices (NDVI, TCA) and derivative values $\left(\mathrm{PI}_{\mathrm{TCA}}, \mathrm{PI}_{\mathrm{NDVI}}\right.$ ) are employed as ordering features, as proxies to biomass and biomass changing properties (Table 4). We attempted a series of a priori reasonable proxies and created 14 spectral systems with spectral trajectories linked to ground plots. The process of attribution was based on identification of most similar pattern; with this purpose each system of curves was compared with the model counterparts. Since optimal proxies are not identified in advance, a priori various pairings are feasible: for instance system A1 curves (ordered by $\mathrm{PI}_{\mathrm{TCA}-1990}$ - the value of TCA derivative at date 1990) were compared with models in M1 to M5 (five comparisons), system N11 curves (ordered by NDVI ${ }_{1990}$ ) were compared with models in M14 to M16 (three comparisons) and so on (Table 4). Fifty-eight combinations (18 state and 40 process) were possible. The number of spectral trajectories (N2) necessary to develop a suitable system is not fixed, but should be enough to be fitted for the wavelet transform parameters. For the sake of verification, the same set of ground plots previously used to build the curve models (AGB known case) are now attributed (AGB unknown case). 
Table 4. Dynamic variables derived by transformation of spectral trajectories with a $2 D$ wavelet smoothing of an ordered system. Fifty-eight combinations resulted from pairing sample systems (AGB unknown case) and model systems (AGB known case).

\begin{tabular}{|c|c|c|c|c|c|}
\hline \multirow[b]{2}{*}{$\begin{array}{l}\text { Group of } \\
\text { dynamic } \\
\text { variables }\end{array}$} & \multirow[b]{2}{*}{$\begin{array}{c}\text { Spectral } \\
\text { index }\end{array}$} & \multicolumn{2}{|c|}{ VARIABLE CONSTRUCTION } & \multicolumn{2}{|c|}{ ATTRIBUTION } \\
\hline & & $\begin{array}{c}\text { Model } \\
\text { ordering } \\
\text { attribute }\end{array}$ & $\begin{array}{l}\text { Variable } \\
\text { identifier } \\
\text { (\# domain } \\
\text { patterns) }\end{array}$ & $\begin{array}{c}\text { Independent } \\
\text { ordering attribute } \\
\text { (biomass feature } \\
\text { proxy) }\end{array}$ & $\begin{array}{c}\text { System } \\
\text { identifier }\end{array}$ \\
\hline \multirow{6}{*}{$\begin{array}{c}\text { State } \\
\text { (Trajectory } \\
\text { 1984-2009) }\end{array}$} & \multirow{3}{*}{ TCA } & $\mathrm{AGB}_{1990}$ & M11 (6) & $\mathrm{TCA}_{1990}$ & A11 \\
\hline & & $\mathrm{AGB}_{2000}$ & M12 (8) & TCA $_{1984}$ & A12 \\
\hline & & $\triangle \mathrm{AGB}$ & M13 (8) & TCA $_{2004}$ & A13 \\
\hline & \multirow{3}{*}{ NDVI } & $\mathrm{AGB}_{1990}$ & M14 (7) & $\mathrm{NDVI}_{1990}$ & N11 \\
\hline & & $\mathrm{AGB}_{2000}$ & M15 (7) & $\mathrm{NDVI}_{1984}$ & N12 \\
\hline & & $\triangle \mathrm{AGB}$ & M16 (7) & $\mathrm{NDVI}_{2004}$ & $\mathrm{~N} 13$ \\
\hline \multirow{10}{*}{$\begin{array}{c}\text { Process } \\
\text { (Derivative } \\
\text { 1984-2009) }\end{array}$} & \multirow{5}{*}{ TCA } & $\Delta \mathrm{AGB}$ & M1 (7) & $\mathrm{PI}_{\mathrm{TCA}-1990}$ & A1 \\
\hline & & $\operatorname{Rel}_{1990}$ & M2 (7) & mean $\mathrm{PI}_{\mathrm{TCA}-1990-2004}$ & A2 \\
\hline & & $\operatorname{Rel}_{2000}$ & M3 (7) & $\mathrm{PI}_{\mathrm{TCA}-1995}$ & A3 \\
\hline & & $\mathrm{AGB}_{1990}$ & M4 (8) & $\mathrm{PI}_{\mathrm{TCA}-2004}$ & A4 \\
\hline & & $\mathrm{AGB}_{2000}$ & M5 (8) & & \\
\hline & \multirow{5}{*}{ NDVI } & $\triangle \mathrm{AGB}$ & M6 (7) & $\mathrm{PI}_{\mathrm{NDVI}-1990}$ & N1 \\
\hline & & $\operatorname{Rel}_{1990}$ & M7 (8) & mean $\mathrm{PI}_{\text {NDVI-1990-2004 }}$ & $\mathrm{N} 2$ \\
\hline & & $\operatorname{Rel}_{2000}$ & M8 (8) & $\mathrm{PI}_{\text {NDVI-1995 }}$ & $\mathrm{N} 3$ \\
\hline & & $\mathrm{AGB}_{1990}$ & M9 (8) & $\mathrm{PI}_{\mathrm{NDVI}-2004}$ & N4 \\
\hline & & $\mathrm{AGB}_{2000}$ & M10 (7) & & \\
\hline
\end{tabular}

Trajectories are compared with the model curves of coupled systems, which are uniquely identified with a categorical value, and the most similar pattern is assumed and adopted at each plot. For example the 573 curves in system A1 are compared to seven model patterns in M1, each one acquiring the value of the most similar M1 pattern. Similarity was evaluated with the Dynamic Time Warping (DTW) (Giorgino, 2009), a flexible algorithm for alignment of vectors (e.g. time series). DTW compares and evaluates the difference between series of values, and it is more sensitive than the Euclidean distance to distortion in the time axis (Ratanamahatana and Keogh, 2005) allowing certain stretch or compression defined by user criteria, such as delays in a curve maxima or minima. At the end of the attribution process each plot is characterized with 58 curve patterns, some of which might be relevant to describe its AGB, as linked to a particular successional path.

\subsection{Decision trees for modelling historical AGB}

With ground plots characterized by dynamic variables, we can test the ability of these variables to predict AGB by statistical modelling. Decision trees (Breiman et al., 1984), also known as CART, identify relationships between a single continuous response variable (AGB) and multiple explanatory variables of 
either continuous and/or discrete character, in our case a collection of static (NDVI and TCA at various dates) and dynamic variables (Table 5). A binary recursive partitioning process based on combinations of variables (rules) that best distinguish the variation of AGB enables identification of relevant independent predictors. This nonparametric method for categorization of samples into increasingly homogeneous groups (nodes) does not make assumptions regarding the distribution of the input data and is robust to errors in the input. Decision trees have been widely used for predicting complex, nonlinear relationships between forest attributes and remotely sensed images (e.g. Saatchi et al., 2007).

Each plot was characterized with the biomass attributes (Table 2), the spectral indices at various dates (Figure 1, box 3), and its most similar patterns of dynamic variables in the 25-year and 15-year versions (Table 5). These sets of data were input for the CART analysis in Matlab® (Figure 1, box 4). Samples were split into calibration (50\%) and validation (50\%) sets, assuring both sets covered the entire range of AGB (1 to $350 \mathrm{t} \mathrm{ha}^{-1}$ ). To fit the model, a cross-validation process with ten iterations was performed and to avoid over-fitting, we considered the establishment of a minimum number of cases in terminal nodes and pruning with the 1 standard error rule (Breiman et al., 1984).

Table 5. Input variables to decision trees for modelling historical AGB in pines of central Spain.

\begin{tabular}{|c|c|c|}
\hline Character & Nature & Variables \\
\hline Static & Spectral indices & $\begin{array}{l}\text { TCA 1984, 1990, 2000, 2004, } 2009 \\
\text { NDVI 1984, 1990, 2000, 2004, } 2009 \\
\text { TCD 1984, 1990, 2000, 2004, } 2009\end{array}$ \\
\hline \multirow{2}{*}{ Dynamic } & State patterns (18) & $\begin{array}{l}\text { TCA related trajectory 1984-2009 } \\
\text { NDVI related trajectory 1984-2009 }\end{array}$ \\
\hline & Process patterns (40) & $\begin{array}{l}\mathrm{PI}_{\mathrm{TCA}} \text { related trajectory 1984-2009 } \\
\mathrm{PI}_{\mathrm{NDVI}} \text { related trajectory } 1984-2009\end{array}$ \\
\hline
\end{tabular}

\subsection{Mapping historical AGB dynamics and validation}

To map and assess the biomass and carbon content over the entire area, AGB models derived at the plot level (5x5 pixel window) were applied to spatial units defined on the Landsat image as small multi-pixel objects, within which the spectral trajectory is the average of the component pixels (Figure 1, box 5). As we aim to derive AGB maps for years 1990 and 2000, contemporaneous images were individually segmented with Definiens Cognition Network Technology® (Baatz and Schäpe, 2000; Definiens, 2005) (scale parameter 1.5; color-shape 0.9-0.1; smoothness 0.5; homogeneity based on Landsat bands 3, 4, and 5) into objects of 3.1 ha and 2.5 ha on average, in the same scale range of the $5 \times 5$ pixels window used for modelling. Objects were characterized with static and dynamic predictors and classified following the best decision tree model rules. Through this process each spatial object acquired an AGB (t ha-1) value and its related standard deviation as a measure of uncertainty. 
Among other advantages, pixel-based mapping facilitates comparisons and evaluation of change with direct algebraic calculations, and it offers the option to define aggregation units for particular applications. Pixel-based maps were derived from the object maps initially produced: each pixel was assigned the AGB ( $\left.\mathrm{t} \mathrm{ha}^{-1}\right)$ and uncertainty $\left(\mathrm{E}_{1990}, \mathrm{E}_{2000}\right)$ values of the object it belongs to, and from these maps the AGB change ( $\triangle \mathrm{AGB}$ ) map was derived (Figure 1, box 6). The $\triangle \mathrm{AGB}$ map consists of three layers: a main map evaluated by differences in pixel nominal values and two other layers depicting scenarios of maximum added uncertainty (eq. 1).

$\Delta \mathrm{AGB}=\left(\mathrm{AGB}_{2000}-\mathrm{AGB}_{1990}\right) \pm\left(\mathrm{E}_{1990}+\mathrm{E}_{2000}\right)$

eq. 1

Detailed maps of carbon stock and carbon flux due to biomass change over the period 1990-2000 can then be derived from the biomass maps using a 0.5 multiplier of AGB to carbon (Kollmann, 1959; Penman et al., 2003). As a standard, this biomass to carbon relation is widely used (e.g. Krankina et al., 2004; Houghton et al., 2007) and enables comparison and reporting of regional and global carbon stocks (e.g. Keith et al., 2009; Houghton, 2005).

In order to validate the raster map of change, it was cross checked with the original values of plot $\Delta \mathrm{AGB}$ distributed into six categories. To identify sources of confusion we used an error matrix with an expanded diagonal, deemed adequate for this continuum classification established with artificial hard class breaks (Congalton and Green, 2009) (Table 7).

\section{Results}

\subsection{Ground plot attributes derived from NFI measures}

There were more eligible trees ( $\mathrm{D}>7.5 \mathrm{~cm}$ ) for measurement in the NFI3 (ca. 2000) than in the previous rotation of the inventory in this area (NFI2, ca. 1990). Increments are particularly marked for the larger diameter classes, resulting in an expected increase in AGB during the period 1990-2000. However, the distribution of AGB ( $\mathrm{t} \mathrm{ha}^{-1}$ ), as derived from field measures in NFI plots (Figure 5) is similar at both dates, unimodal and positively skewed, with a majority of plots around $50 \mathrm{t} \mathrm{ha}^{-1}$ and median values of 59 and $77 \mathrm{t} \mathrm{ha}^{-1}$ in NFI2 and NFI3 respectively. The indicators of structural complexity are distributed over very different scales, with a potentially more relevant $D_{\text {MAD }}$ ranging from 0 to 24 while $H_{M A D}$ ranges between 0 and 8 . We show in Figure 5 the distributions of standardized values of $D_{M A D}$ and $H_{M A D}$. 

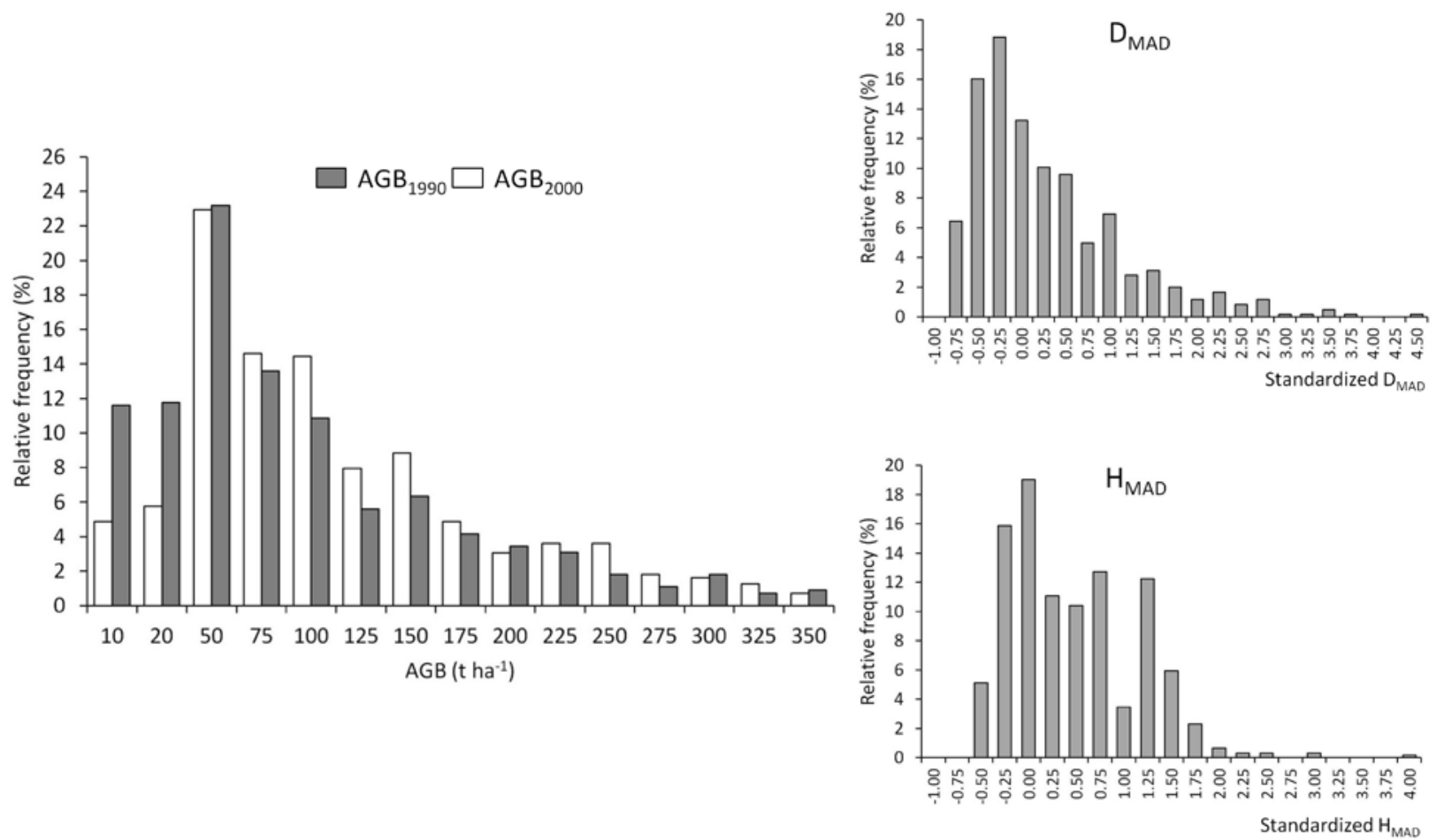

Figure 5. Distribution of AGB at two rounds of NFI (ca. 1990 and ca. 2000) and standardized structural diversity indicators (DMAD and HMAD) in 1990.

\subsection{Relationship between ground plot estimates of AGB and spectral vegetation indices}

Our exploration of the relationship between vegetation spectral indices and AGB through wavelet transformations revealed an underlying strong connection, influenced by forest structural complexity (expressed by the diversity of ground plot measured diameters and heights) and affected by exogenous factors. Level six of the Meyer based discrete wavelet transform decomposition had the highest variance: it contributes the most to the overall variability in the original series and therefore has the highest explanatory power. After the first quartile of increasing AGB, NDVI and TCA approximation functions follow an almost coincident trend (Figure 6, left). The relationship of TCD with AGB is strongly influenced by forest structure, in particular by local diversity of diameter and height (Figure 6, right) and it is not constant over time as was observed in the $\mathrm{TCD}_{\text {block }}$. At higher levels of wavelet transform decomposition (level 7 and 8) curves flatten on the end corresponding with the plots with the largest amount of biomass, pointing to radiometric saturation at high levels of biomass. We interpret the strong wavy effect observed in all curves, quasi coincident when corrected by structure, as an influence of forest cover and/or variation in terrain features (i.e. elevation, slope, and orientation). 

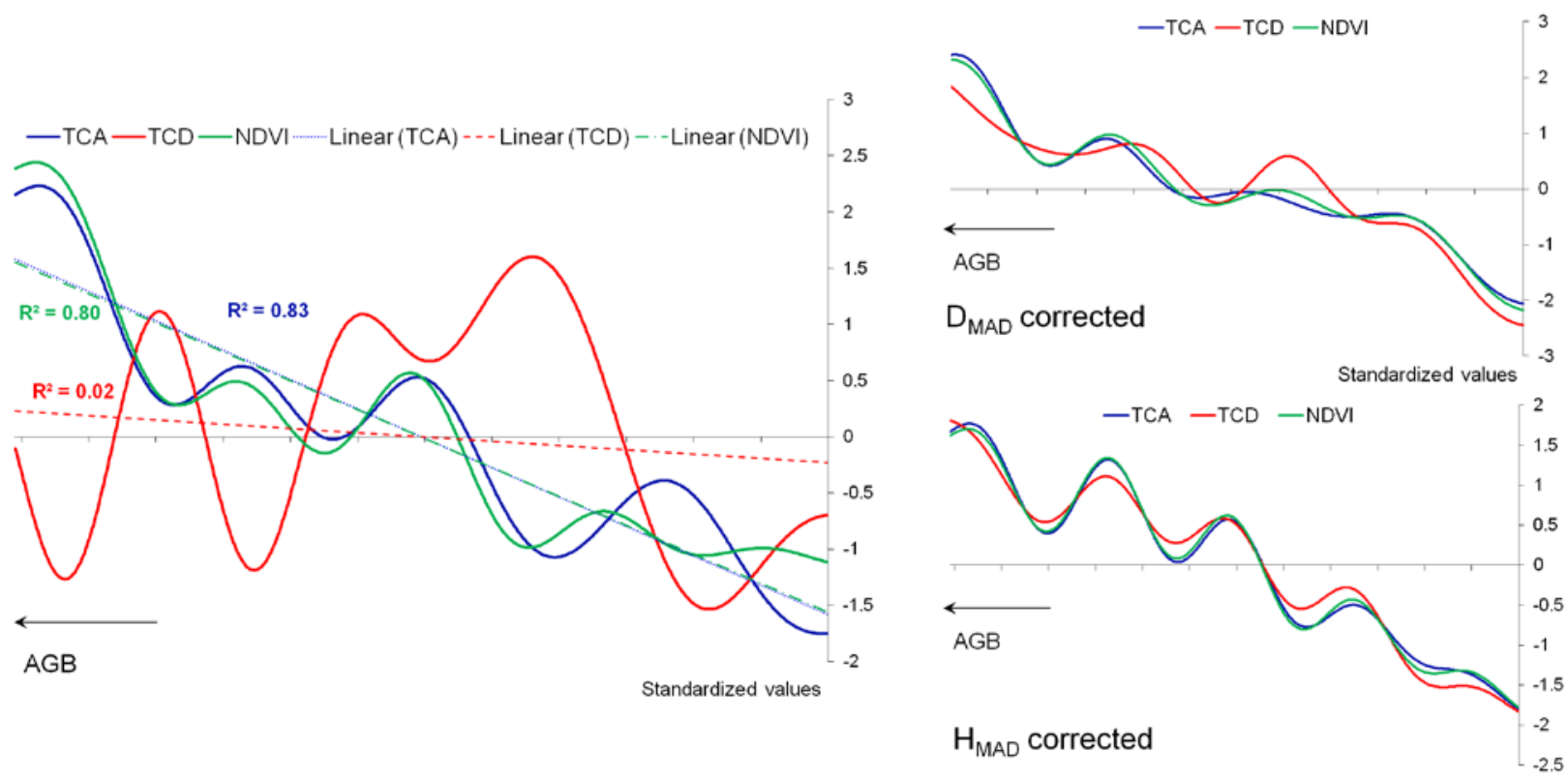

Standardized values

Figure 6. Approximation 6 of the Discrete Wavelet Transformation (DWT) decomposition of vegetation spectral indices (NDVI, TCA, TCD) as a function of AGB. Left: NDVI and TCA follow a similar nonlinear trend with increasing AGB, whilst TCD evidences a different type of relationship. Right: same as left but spectral indices are corrected with structural diversity factors (DMAD and HMAD) to show their weight on the relationship.

When analysing the sub-sample of 182 plots regularly distributed every $\sim 1.7 \mathrm{t} \mathrm{ha}^{-1}$ over the range $1-310 \mathrm{t}$ $\mathrm{ha}^{-1}$, the detail function of level five revealed some sections with maximal variation found at regular intervals, suggesting categories equivalent to $\sim 50 \mathrm{t} \mathrm{ha}^{-1}$. Only the $\mathrm{NDVI}_{\text {block }}$ showed an apparent stability of these groups over time.

\subsection{Decision trees for modelling historical AGB}

In building the decision trees for modelling AGB, different combinations of predictor variables were tested (Table 6) and the relevance of each group of variables was evaluated. All fitted models were statistically significant ( $p$-value < 0.001) but exhibited variable levels of correlation between AGB and the spectral predictors (Table 6). Models were applied to the independent set of data for validation and their performance was assessed with the Root Mean Square Error (RMSE), the correlation coefficient $\left(\mathrm{R}^{2}\right)$, percentage average error (ME), and bias. 
Table 6. Summary of modelling results when including different sets of variables. NDVI process patterns are best predictors. The entire 25-year pattern variables yield more accurate and precise results than the 15-year pattern variables, but a combination of both yields best results.

\begin{tabular}{|c|c|c|c|c|c|c|}
\hline & \multicolumn{3}{|c|}{ Fitting } & \multicolumn{2}{|c|}{ Validation } & \multirow[b]{2}{*}{ Bias } \\
\hline & Variable & $\mathbf{R}$ & $\mathbf{R}^{2}$ & RMSE (t ha-1) & \% Mean error & \\
\hline \multirow{7}{*}{$\mathrm{AGB}_{1990}$} & All & 0.95 & 0.90 & 32.2 & 0.34 & 0.99 \\
\hline & 25-year pattern & 0.84 & 0.68 & 58.7 & 0.62 & 1.02 \\
\hline & 15-year pattern & 0.76 & 0.54 & 70.9 & 0.74 & 1.01 \\
\hline & NDVI pattern & 0.94 & 0.89 & 32.2 & 0.36 & 0.99 \\
\hline & TCA pattern & 0.29 & - & - & - & - \\
\hline & State trajectory & 0.22 & - & - & - & - \\
\hline & Static indices & 0.18 & - & - & - & - \\
\hline \multirow{7}{*}{$\mathrm{AGB}_{2000}$} & All & 0.73 & 0.53 & 71.6 & 0.65 & 0.96 \\
\hline & 25-year pattern & 0.65 & 0.40 & 79.1 & 0.72 & 0.93 \\
\hline & 15-year pattern & 0.58 & 0.26 & 87.9 & 0.80 & 0.95 \\
\hline & NDVI pattern & 0.65 & 0.41 & 78.0 & 0.71 & 0.92 \\
\hline & TCA pattern & 0.18 & - & - & - & - \\
\hline & State trajectory & 0.22 & - & - & - & - \\
\hline & Static indices & 0.17 & - & - & - & - \\
\hline
\end{tabular}

Trees yielding better results (higher $\mathrm{R}^{2}$, and lower RMSE, ME, and bias) include decision rules based on process and state patterns. Moreover, the best fitted tree $(\mathrm{R}=0.95)$ combines 25- and 15-year NDVI process variables (Figure 7). When validated, this model shows high $\mathrm{R}^{2}$ and a small bias towards underpredictions; with a RMSE of $32 \mathrm{t} \mathrm{ha}^{-1}$ it produces errors of $34 \%$ on average. Modelling options that include either 25- or 15-year patterns are not optimal; however, the model based on the entire 25-year trajectory patterns yields better results. Static indices alone or together with state trajectories did not model biomass satisfactorily, they produced low correlations. Interestingly we found NDVI process patterns more relevant than the analogous TCA patterns in describing historical AGB, despite a similar relationship of either static index with biomass.

Decision trees modelling $\mathrm{AGB}_{1990}$ have a common feature, a first split of plots with AGB $>100 \mathrm{t} \mathrm{ha}^{-1}$ (31\% of the sample) into one branch and plots with AGB $<100 \mathrm{t} \mathrm{ha}^{-1}$ (69\% of the sample) into the other branch (Figure 7). Unless restricted by selective inclusion of predictors, the initial split is determined by a rule based on an NDVI process pattern: in other words, the rate of stand development is the most relevant factor for identifying plots with large amounts of AGB (which are presumably more mature) from low AGB (and frequently younger) plots. The criteria for further splitting the group of plots with more than $100 \mathrm{t} \mathrm{ha}^{-1}$ of biomass include process patterns associated with relative ( $\left.\triangle \mathrm{AGB} / \mathrm{AGB}_{2000}\right)$ and absolute change ( $\triangle \mathrm{AGB}$ ) of AGB. The group of low AGB plots (i.e. $<100 \mathrm{tha}^{-1}$ ) is further categorized by patterns 
associated with $\mathrm{AGB}_{1990}$ and $\mathrm{AGB}_{2000}$ ) (Table 4). Just one static index, the $\mathrm{TCA}_{1990}$, was present in an accurate classification of the ground plot biomass. Five out of the six terminal nodes in the best fitting tree are defined by 25-year patterns, highlighting the convenience of longer term information. In only one case was a TCA pattern of change used to split the largest branch in the decision tree.

For interpretation of the dynamic predictors and to associate them with ecological change and forest succession, their relative value acquired by normalization and scaling requires consideration. For instance, the plots with the larger values of AGB in 1990 are related with a pattern characterized by a constant and relatively low speed of NDVI variation, positive over most of the period 1990-2004, (it appears constant and close to maximum in the scaled curve (model 3 in Figure 4, bottom)). This is in agreement with expectation from a relatively mature and healthy closed canopy stand. Other patterns of this predictor that identify plots with relatively low AGB represent a varying speed of change, with minimum and maximum at specific locations: for instance the plots with the lowest AGB are characterized by a pattern that goes from an absolute minimum speed of NDVI variation $\left(\mathrm{PI}_{\mathrm{NDVI}}\right)$ in 1990 to an absolute maximum $\mathrm{PI}_{\mathrm{NDVI}}$ after only a few years, followed by stabilization probably associated with the closing of the canopy.

We assessed the capacity of individual dynamic predictors for classifying AGB and found that patterns derived from spectral systems ordered by AGB are the most powerful. Patterns based on AGB $_{1990}$ and defining eight groups of biomass classified correctly $31 \%$ of the plots, with $51 \%$ within \pm 1 group (and $70 \%$ within \pm 2 groups).

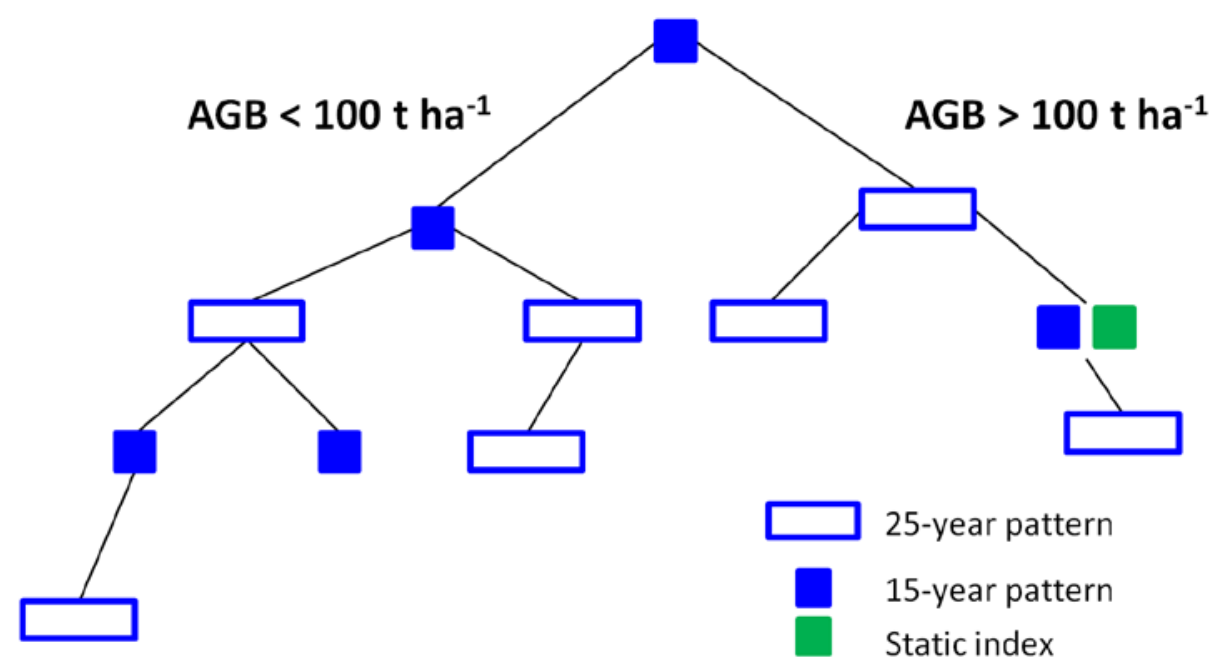

Figure 7. Schematic representation of an optimal decision tree for classification of $A G B_{1990}$. The tree combines decision rules based on 25- and 15-year patterns. A main division splits the sample into ground plots with $A G B>100 t h a^{-1}$ and $A G B<100 t h a^{-1}$. 
With a similar procedure we classified plots according to their biomass at a date corresponding with the NFI3 (ca. 2000). In this case the biophysical attribute is modelled with the history of spectral indices and a collection of past and prospective changing patterns, testing a different temporal configuration (Figure 9). Results of modelling $\mathrm{AGB}_{2000}$ are more restricted, with statistically significant (p-value $<0.001$ ) best fitting trees having a correlation with the sample of $\mathrm{R}=0.73$. Models show a general tendency to underestimate AGB, and have limited predictive power $\left(\mathrm{R}^{2}=0.53\right)$. With high ME $(70 \%)$ these models are limited for estimation of biomass in the area. Still, the variables related with changing processes have stronger predictive power than those related with state, which reinforces the importance of the rate of change to model development. Attempts to model absolute ( $\triangle \mathrm{AGB})$ and relative $\left(\operatorname{Rel}_{1990}, \mathrm{Rel}_{2000}\right)$ change of biomass were unsuccessful, with no direct relation between these variables and the estimators considered.

\subsection{Mapping historical AGB dynamics and validation}

In the process of mapping $\mathrm{AGB}_{1990}, 26,406$ objects resulted from segmentation of the contemporaneous Landsat image, $40.4 \%$ of which $(10,693)$ was classified by the decision tree branch of larger AGB values ( $>100 \mathrm{t} \mathrm{ha}^{-1}$ ). Ninety-five percent of objects achieved terminal nodes of the decision tree, indicating consistency in the up-scaling from plot-level model to object-level classification: all combinations of the relevant spectral trajectories characterizing AGB at the plot level correspond with combinations of averaged spectral trajectories of spatial objects with the same AGB $\left(\mathrm{t} \mathrm{ha}^{-1}\right)$.

The biomass allocated in the aboveground fraction of trees in year 1990 was on average $77.6 \mathrm{t} \mathrm{ha}^{-1}$ (total in the area amounts $\left.6295 \times 10^{3} \mathrm{t}\right)$, and it was estimated to be $91.5 \mathrm{t} \mathrm{ha}^{-1}\left(7415 \times 10^{3} \mathrm{t}\right)$ ten years later (2000). The difference of calculated AGB represents an increment of $1.3 \mathrm{t} \mathrm{ha}^{-1} \mathrm{y}^{-1}$ on average and the total increase in the area is equivalent to $560 \times 10^{3} \mathrm{t}$ of $\mathrm{C}$. Considering individual objects imprecision, global values of $\mathrm{AGB}_{1990}$ and $\mathrm{AGB}_{2000}$ range between 5.5 and $7.1 \times 10^{6} \mathrm{t}$ and between 3.4 and $11.3 \times 10^{6} \mathrm{t}$ respectively, and as expected from the modelling results, the later date contributes notably more to the uncertainty of estimated change. By means of the multilayer raster maps we evaluated total change in the case scenarios of additive uncertainties derived from modelling and mapping, obtaining values of $2.9 \mathrm{t} \mathrm{ha}^{-}$ ${ }^{1} \mathrm{y}^{-1}$ loss and $8.5 \mathrm{t} \mathrm{ha}^{-1} \mathrm{y}^{-1}$ gain on average. A detail of the multilayer maps of biomass change in Figure 8 shows the spatial distribution and variability that exists, information of crucial value for management. 


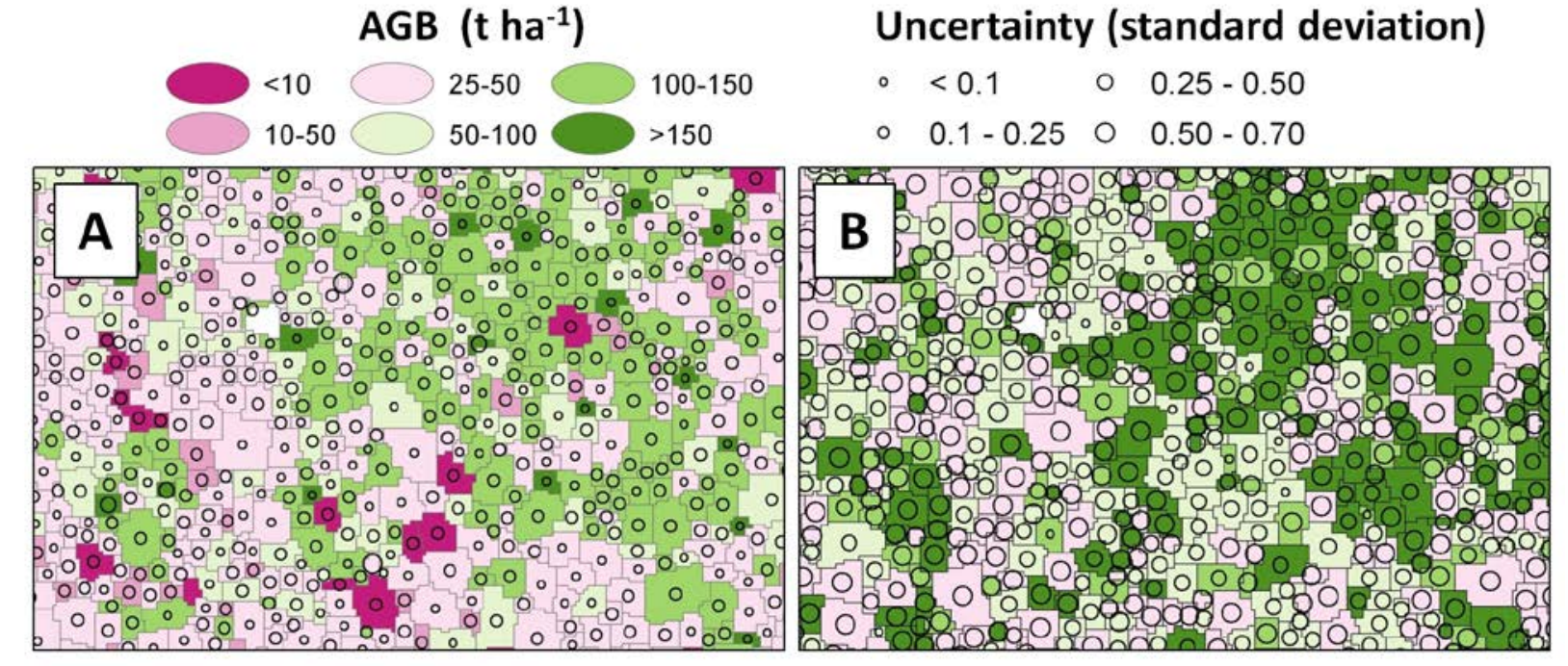

\section{Uncertainty (standard deviation)}
- $<0.1$
○ $0.25-0.50$
$\circ \quad 0.1-0.25 \circ 0.50-0.70$
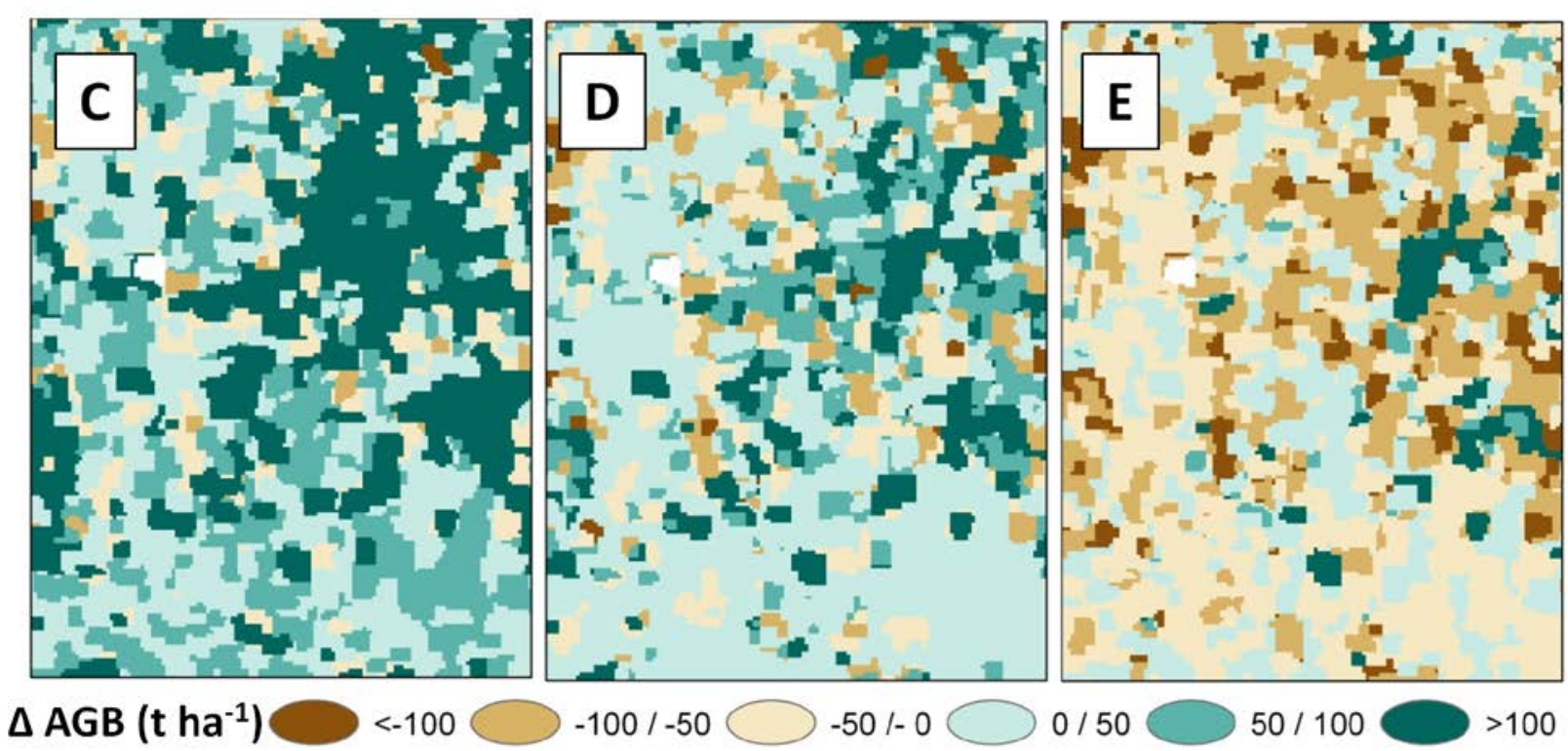

$\triangle \mathrm{AGB}\left(\mathrm{t} \mathrm{ha}^{-1}\right)$

$-100 /-50$

$-50 /-0$

$0 / 50$

(50/100

100

Figure 8. Top: detail of the object based biomass maps in 1990 (A) and 2000 (B). Bottom: detail of multilayer $\triangle A G B$ maps showing spatial distribution and variability of change. (C) optimistic result derived from uncertainty; (D) nominal change; (E) pessimistic result derived from uncertainty.

Validating the raster map of change by cross checking with the original values of plot $\triangle \mathrm{AGB}$ distributed into six categories, low producer's (21-27\%) and user's (16-23\%) errors are recorded in intermediate categories (Table 7). However, the distribution of values in the matrix point to a slight tendency to overestimate incremental biomass. Overall, $70 \%$ of checked points were classified into the correct category of AGB change. 
Table 7. Accuracy matrix of the raster map of biomass change categories.

\begin{tabular}{|c|c|c|c|c|c|c|c|}
\hline \multicolumn{8}{|c|}{ Plot change ( $\mathrm{t} \mathrm{ha}^{-1}$ ) (reference) } \\
\hline & $<-100$ & $-100 /-50$ & $-50 / 0$ & $0 / 50$ & $50 / 100$ & $>100$ & User's metrics \\
\hline$<-100$ & 0 & 0 & 2 & 1 & 0 & 0 & 0 \\
\hline$-100 /-50$ & 3 & 1 & 10 & 33 & 8 & 0 & 0.25 \\
\hline$-50 / 0$ & 3 & 2 & 11 & 28 & 9 & 0 & 0.77 \\
\hline $0 / 50$ & 14 & 15 & 50 & 143 & 53 & 17 & 0.84 \\
\hline $50 / 100$ & 3 & 7 & 16 & 61 & 8 & 5 & 0.74 \\
\hline$>100$ & 2 & 3 & 8 & 26 & 8 & 1 & 0.19 \\
\hline $\begin{array}{l}\text { Producer's } \\
\text { metrics }\end{array}$ & 0.12 & 0.11 & 0.73 & 0.79 & 0.80 & 0.26 & 0.70 \\
\hline
\end{tabular}

\section{Discussion}

Historical forest aboveground biomass was modelled, evaluated, and mapped in Mediterranean pines of Spain combining a set of NFI plots representative of the forest conditions present and spectral data captured by Landsat sensors over a period of 25 years (1984-2009). As a baseline for comparison with more recent estimates, an assessment of past AGB with spatial detail is of value to support monitoring and reporting commitments. In this area, characterized by absence of major perturbations and moderate human intervention during succession stages, dynamic variables of change (i.e. predictors combining data captured at various dates), showed higher predictive capacity than static variables to explain the variability of AGB retrospectively.

Spectral response is related to forest structure (Cohen et al., 1995) and develops progressively with successional state (Peterson and Nilson, 1993). Under equal environmental conditions and absent disturbance, forest stands develop similarly and are expected to show similar temporal spectral trajectories, although slight deviations from a pattern may exist. However, although forest attributes have been modelled accurately with spectral variables, forest change remains elusive for direct modelling: spectral differences alone have demonstrated inadequate for the purpose (Healey et al., 2006), and trends of spectral trajectories do not necessarily have a direct relation with the increase or decrease of biomass (Campbell et al., 2012).

Our previous attempts to model biomass in the Central Range of Spain with single date optical data were limited, characterized by moderate fitting correlation $(\mathrm{R}=0.7)$ and $\mathrm{ME}$ of 0.78 (Gómez, 2006). Also in the same area, Vázquez de la Cueva (2008) found structural parameters (canopy crown closure, stand height, stem density, and basal area) insufficiently explained by the multispectral predictors selected to derive 
empirical models; however, the Tasseled Cap Wetness had a stronger relation with forest density than NDVI or other TM/ETM+ bands. Interestingly, in this work we have found TCA significant as static variable, while patterns associated with NDVI were relevant as process variables. The TCD, more related to age and associated structural complexity than other Tasseled Cap-related indices in coniferous forests of Oregon, USA (Duane et al., 2010) was also found linked to forest complexity in these Mediterranean pines, despite a low correlation between AGB and parameters of structural complexity (Pearson's R of 0.22 , 0.24, with $\mathrm{D}_{\mathrm{MAD}}$ and $\mathrm{H}_{\mathrm{MAD}}$ respectively). In view of local difficulties to directly model forest attributes, we applied mathematical transformations based on 2D wavelet algorithms to a data-system created with information from two rounds of field measures and eight repetitions of calibrated spectral data, filtering fundamental relations from environmental and endogenous noise. Dynamic variables (i.e. variables with an inherent temporal component) associated with patterns of change, including rate and shape, characterized ground plots, and together with static variables served to model AGB and calculate AGB dynamics. This approach significantly improved previous results, but no single predictor was able to accurately classify biomass.

Frequency and regularity of measurements can be critical in providing an accurate understanding of ecological processes. Gaps in a series of measures and irregular data frequencies leave intervals of uncertainty in explaining continuous processes that might be notable in ecosystems prone to rapid changes related to disturbance (Jin and Sader, 2005). Successional patterns are more predictable in undisturbed forests than in areas with unexpected perturbations (Schroeder et al., 2007; Vogelmann et al., 2009) and the rate of spectral variation is typically greater in immature stands when compared to more mature stands in similar environments. Wavelet transform analysis is particularly suited to detect anomalies in series of data (Mallat and Hwang, 1992) and does not require periodic sampling (Daubechies et al., 1999), conferring this approach versatility for analysis of data in a wide range of environments. The limited number of seasonally appropriate, cloud-free images available at the time of this study is not necessarily indicative of the full Landsat archive, which the USGS is currently consolidating with unique images held by International Cooperators (Loveland and Dwyer, 2012). As of writing, the European Space Agency has yet to provide Landsat data through the free and open access model demonstrated by the USGS. Reportedly there are plans to share these European images with the USGS, which when implemented, will improve the density of images available over Europe.

The temporal configuration (i.e. the duration, starting point, and position relative to the target date) of the dynamic variables (Figure 9) presumably affects the capacity to predict structural and successional forest attributes, as suggest different results in modelling AGB in 1990 and 2000. AGB $_{1990}$ corresponds with the 
initial stages of a trajectory to resemble one of a series of temporal patterns, with possible deviations or delays of key features. Deviation of forest stands from standard expectations of development is often related to site index differences, canopy cover and density, or species characteristics, factors requiring attention when deriving, applying, and interpreting model results. Alternatively, $\mathrm{AGB}_{2000}$ corresponds with an intermediate position of the available spectral trajectories, with which processes are not aligned. The duration of spectral trajectory necessary to identify significant temporal patterns in AGB is presumably variable and site dependent. Liu et al. (2008) demonstrated that a series of images covering a longer period predicts forest age more accurately, but in some cases a shorter time series of imagery may suffice. In this work a combination of 25-year and 15-year trajectories was the best option for estimating retrospective AGB. Longer-term patterns may potentially explain the variability of AGB more precisely, but they may also introduce irregularities outside the time lapse between data used for calibration of the trajectory models; on the other hand, shorter-term patterns are more explicit and less prone to variations out of the reference period. Further work is necessary to clarify the distinctive effect that duration and relative location of spectral trajectories produce when employed as dynamic variables. Another set of ground plot measures (NFI4 ca. 2010) in this area is expected to be released shortly, with available spectral data completing the temporal series to that date and beyond (Figure 9). Hence the duration, starting point, and temporal character (retrospective, prospective or inclusive) of the trajectory will be available for further exploration.

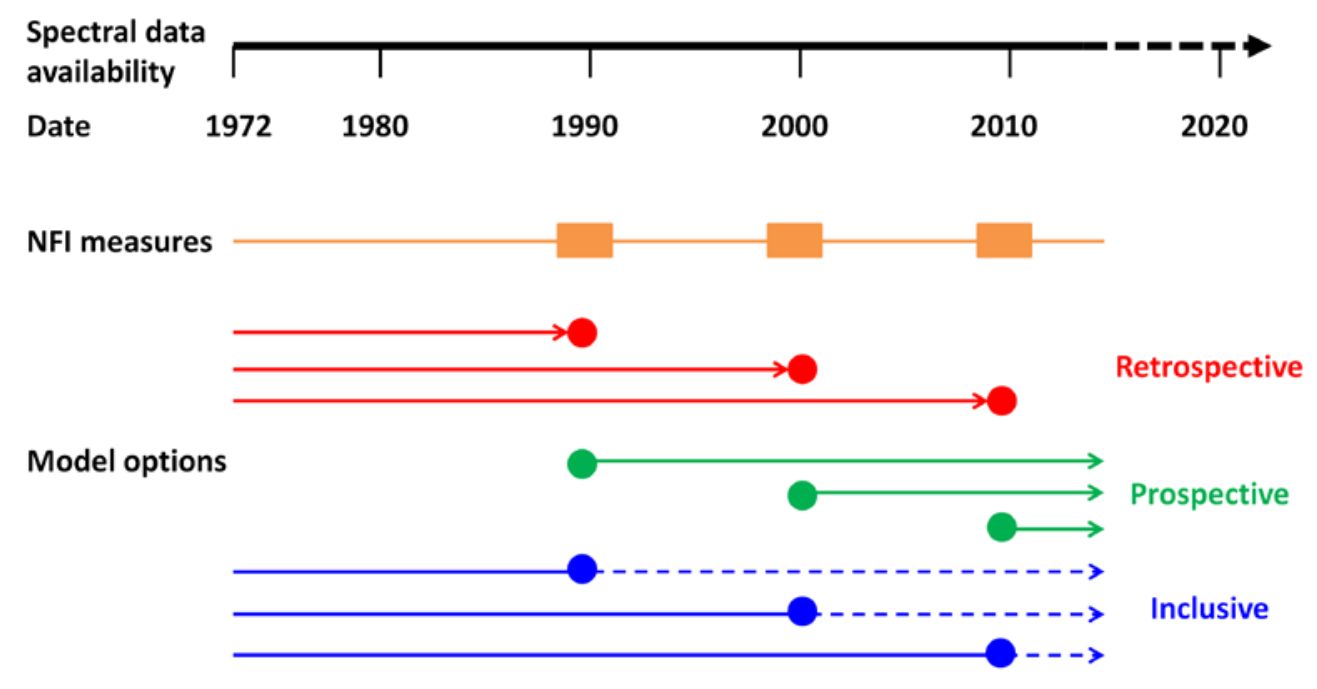

Figure 9. Schematic of options to investigate temporal configurations of dynamic predictor variables. Circles indicate dates to model; arrows indicate the end point of spectral trajectories. Retrospective case: the trajectory interval is prior to the modelled date; prospective case: the trajectory interval is posterior to the modelled date; inclusive: previous and subsequent intervals of spectral trajectories are used to model and intermediate date attributes. 
We chose Dynamic Time Warping (DTW) as a measure of series similarity for its documented optimal performance in fields like speech pattern recognition (Velichko and Zagoruyko, 1970) or clustering of gene expression profiles (Aach and Church, 2001), but the superiority of this measure over others in identification of patterns of forest spectral trajectories has not been widely demonstrated. Both the robustness of the DTW measure and the automation of pattern identification require further investigation.

The uncertainty reported in the final maps possibly originates from imprecision in modelling, but could also have originated at various stages of the overall approach, including location of plots, field measures, allometric equations, image capture, and image processing (Lu et al., 2012). To minimize the impact of these factors, a representative sample acquired to consistent specifications, such as NFI plots, is recommended for modelling (Duane et al., 2010), and necessary to obtain a comprehensive domain of trajectory patterns for accurate identification by the similarity algorithm. We identified confusion in the final map of change with an inclusive approach of all error sources, but from plot based model to final maps, some aspects could be subject to individual testing, such as the equivalence of pixel and object trajectory or the vector to raster transformation.

Estimates of AGB dynamics between 1990 and 2000 obtained in the current study are in agreement with complementary regional studies. For instance, pines in the Central Range were found to be more dense and mature in year 2000 than during the previous decade, and - as could be expected - accounted a net increment of biomass and carbon stock. Analyzing inputs and outputs recorded by NFI measures, Herrero and Bravo (2012) corroborated a net carbon sinking character between NFI2 and NFI3 rotations, with AGB allocated in pines of $85 \mathrm{t} \mathrm{ha}^{-1}$, while Montero et al. (2004) estimated an annual increment of $0.9 \mathrm{t}$ ha${ }^{1}$ of pine biomass between 1993 and 2003. Gómez et al. (2012) reported a maximum rate of C stocking in this area for year 2000 with a later change of trend towards C loss during the 2000-2010 decade that forthcoming NFI4 measures may help corroborate.

Information provided by Landsat spectral trajectories has been linked to field measurements, which has proven useful for improving the estimation of current biomass and other structural attributes, particularly in ecosystems with stand replacing disturbances (Pflugmacher et al., 2012). Furthermore, spectral trajectories have demonstrated utility for characterizing mountain pine beetle infestations (Goodwin et al., 2010) and for continuous monitoring of forest disturbance (Zhu et al., 2012). In this study, we have found that the identification of temporal patterns in the trajectory of vegetation indices (i.e. dynamic variables) provides useful information to model and explain historical biomass variability. 


\section{Conclusion}

Remote sensing technology supports and enhances the value of national forest inventories for the assessment of biomass and carbon balance, and the Landsat archive in particular is a unique source of spectro-temporal data for modelling and mapping forest attributes. Mathematical transformations of original data are necessary to unveil underlying relations in complex environments, and to derive dynamic variables with explanatory capacity of past and present biophysical conditions. Dynamic process features such as pattern and rate of change were more relevant than static variables in the retrospective estimation of AGB in the Mediterranean pines of central Spain. Pines in these forests were found to have accrued biomass over the decadal monitoring period, representing a net carbon sink. The approach presented herein allows for the retrospective estimation and mapping of AGB in order to establish a historical baseline and enable change reporting.

\section{Acknowledgements:}

National Forest Inventory data are available online, provided by Ministerio de Agricultura, Alimentación y Medio Ambiente (España). Landsat images are available online, provided by the USGS.

\section{References}

Aach, J., Church, G.M., 2001. Aligning gene expression time series with time warping algorithms. Bioinformatics, 17(6), 495-508.

Andersson, K., Evans, T.P., Richards, K.R., 2009. National forest carbon inventories: policy needs and assessment capacity. Climatic Change, 93, 69-101.

Baatz M., Schäpe, M., 2000. Multiresolution segmentation - an optimization approach for high quality multi-scale image segmentation. In: Strobl, J., Blaschke, T.,Griesebner, G. (Eds.), Angewandte Geographische Informations-Verarbeitung XII. Wichmann Verlag,Karlsruhe, pp. 12-23.

Baccini, A., Friedl, M.A., Woodcock, C.E., Warbington, R., 2004. Forest biomass estimation over regional scales using multisource data. Geophysical Research Letters, 31, L10501, doi:10.1029/2004GL019782.

Baccini, A., Friedl, M.A., Woodcock, C.E., Zhu, Z., 2007. Scaling field data to calibrate and validate moderate spatial resolution remote sensing models. Photogrammetric Engineering and Remote Sensing, 73, 945-954.

Barlow, J., Peres, C.A., 2004. Ecological responses to El Niño-induced surface fires in central Brazilian Amazonia: management implications for flammable tropical forests. Philosophical Transactions of the Royal Society, 359, 367-380. 
Barredo, J.I., San-Miguel-Ayanz, J., Caudullo, G., Busetto, L., 2012. A European map of living forest biomass and carbon stock. EUR 25730 EN. Luxemburg: Publications Office of the European Union. JRC77439. DOI: 10.2788/780.

Blackard, J.A., Finco, M.V., Helmer, E.H., Holden, G.R., Hoppus, M.L., Jacobs, D.M., Lister, A.J., Moisen, G.G., Nelson, M.D., Riemann, R., Ruefenacht, B., Slajanu, D., Weyermann, D.L., Winterberger, K.C., Brandeis, T.J., Czaplewski, R.L., McRoberts, R.E., Patterson, P.L., Tymcio, R.P., 2008. Mapping US forest biomass using nationwide forest inventory data and moderate resolution information. Remote Sensing of Environment, 112, 1658-1677.

Bortolot, Z.J., Wynne, R.H., 2005. Estimating forest biomass using small footprint LiDAR data: an individual tree-based approach that incorporates training data. IPRS Journal of Photogrammetry and Remote Sensing, 59, 342-360.

Bravo, F., Río, M., Pando, V., San Martín, R., Montero, G., Ordoñez, C., Cañellas, I., 2000. El diseño de las parcelas del inventario forestal nacional y la estimación de variables dasómetricas. In El Inventario Forestal Nacional, Elemento Clave para la Gestión Forestal Sostenible; Bravo, F., Rio, M., Peso, C. (Eds.), Fundación General de la Universidad de Valladolid: Valladolid, Spain, pp. 19-35.

Breiman, L., Friedman, J.H., Olshen, R.A., Stone, C.J., Classification and Regression Trees; Chapman and Hall/CRC: Boca Raton, FL, USA, 1984; pp. 358.

Campbell, J.L., Kennedy, R.E., Cohen, W.B., Miller, R.F., 2012. Assessing the carbon consequences of western juniper (Juniperus occidentalis) encroachment across Oregon, USA, Rangeland Ecology Management, 5, 223-231.

Canty, M.J., Nielsen, A.A., Schmidt, M., 2004. Automatic radiometric normalization of multitemporal satellite imagery. Remote Sensing of Environment, 91, 441-451.

Cohen, W.B., Spies, T., Fiorella, M., 1995. Estimating the age and structure of forests in a multiownership landscape of western Oregon, U.S.A. International Journal of Remote Sensing, 16(4), 721-746.

Congalton, R.G., Green, K., 2009. Assessing the accuracy of remotely sensed data, principles and practices. Second edition. Boca Raton, FL. CRC Press, 177 pp.

Chávez, P., 1988. An improved dark object subtraction technique for atmospheric scattering correction of multispectral data. Remote Sensing of the Environment, 24, 459-479.

Chirici, G., Barbati, A., Corona, P., Marchetti, M., Travaglini, D., Maselli, F., Bertini, R., 2008. Nonparametric and parametric methods using satellite images for estimating growing stock volume in alpine and Mediterranean forest ecosystems. Remote Sensing of Environment, 112, 2686-2700.

Daubechies, I., 1992. Ten lectures on wavelets. Society for Industrial and Applied Mathematics, 357 pp. 
Daubechies, I., Guskov, I., Schröder, P., Sweldens, W. 1999. Wavelets on Irregular Point Sets, Philosophical Transactions of the Royal Society A: Mathematical Physical and Engineering Sciences, 357 (1760), 2397-2413.

Definiens. 2005, Definiens eCognition Version 5 Object Oriented Image Analysis User 5 Guide, Definiens, AG, Munich, Germany.

Dong, J., Kaufman, R.K., Myneni, R.B., Tucker, C.J., Kauppi, P.E., Liski, J., Buermann, W., Alexeyev, V., Hughes, M.K., 2003. Remote sensing estimates of boreal and temperate forest woody biomass: carbon pools, sources, and sinks. Remote Sensing of Environment, 84, 393-410.

Du, Y., Guindon, B., Cihlar, J., 2002. Haze detection and removal in high resolution satellite image with wavelet analysis, IEEE Transactions on Geosciences and Remote Sensing, 40(1), 210-217.

Duane, M.V., Cohen, W.B., Campbell, J.L., Hudiburg, T., Turner, D.P., Weyermann, D.L., 2010, Implications of alternative field-sampling designs on Landsat-based mapping of stand age and carbon stocks in Oregon forests. Forest Science, 56, 405-416.

Duncanson, L.I., Neimann, K.O., Wulder, M.A., 2010. Integration of GLAS and Landsat TM data for aboveground biomass estimation. Canadian Journal of Remote Sensing, 36 (2), 129-141.

Englhart, S., Keuck, V., Siegert, F. 2011. Aboveground biomass retrieval in tropical forests-The potential of combined X- and L-band SAR data use. Remote Sensing of Environment, 115, 1260-1271.

FAO, 2003. State of the World's forests. Rome, Italy. Available at http://www.fao.org/docrep/005/y7581e/y7581e00.htm (Accessed 8 August, 2013)

FAO, 2010. Global Forest Resources Assessment. Rome, Italy. Available at www.fao.org/forestry/fra/fra2010/en/ (Accessed 8 August, 2013)

Fazakas Z., Nilsson M., Olsson H., 1999. Regional forest biomass and wood volume estimation using satellite data and ancillary data. Agricultural and Forest Meteorology, 98-99, 417-425.

Foody, G.M., Cutler, M.E., McMorrow, J., Pelz, D., Tangki, H., Boyd, D.S., Douglas, I., 2001. Mapping the biomass of Bornean tropical rain forest from remotely sensed data. Global Ecology and Biogeography, 10, 379-387.

Foody, G.M., Palubinskas, G., Lucas, R.M., Curran, P.J., Honzak, M., 1996. Identifying terrestrial carbon sinks: classification of successional stages in regenerating tropical forest from Landsat TM data. Remote Sensing of Environment, 55, 205-216.

Foody, G.M., Boyd, D.S., Cutler, M.E.J., 2003. Predictive relations of tropical forest biomass from Landsat TM data and their transferability between regions. Remote Sensing of Environment, 85, 463-474.

Freitas, R.M., Shimabukuro, Y.E., 2008. Combining wavelets and linear spectral mixture model for MODIS satellite sensor time-series analysis. Journal of Computational Interdisciplinary Sciences, 1(1), 51-56. 
Fukuda, S., Hirosawa, H., 1999. A wavelet-based texture feature set applied to classification of multifrequency polarimetric SAR images, IEEE Transactions on Geoscience and Remote Sensing, 37(5), 2282-2286.

Garguet-Duport, B., Girel, J., Chassery, J.M., Pautou, G., 1996. The use of multiresolution analysis and wavelets transform for merging of SPOT panchromatic and multispectral image data. Photogrammetric Engineering and Remote Sensing, 62(9), 1057-1066.

Gasparri, N.I., Parmuchi, M.G., Bono, J., Karszenbaum, H., Montenegro, C.L., 2010. Assessing multitemporal Landsat 7 ETM+ images for estimating above-ground biomass in subtropical dry forests of Argentina. Journal of Arid Environments, 74, 1262-1270.

Giorgino, T., 2009. Computing and visualizing Dynamic Time Warping alignments in R: the dtw package. Journal of Statistical Software, 31(7), 1-24.

Gemmell, F. 1995. Effects of forest cover, terrain, and scale on timber volume estimation with Thematic Mapper data in a rocky mountain site. Remote Sensing of Environment, 51, 291-305.

Gemmell, F., 1998. An investigation of terrain effects on the inversion of a forest reflectance model. Remote Sensing of Environment, 65, 155-169.

Gemmell, F., 1999. Estimating conifer forest cover with Thematic Mapper data using reflectance model inversion and two spectral indices in a site with variable background characteristics. Remote Sensing of Environment, 69, 105-121.

Gemmell, F., Varjo, J., Strandstrom, M., 2001. Estimating forest cover in a boreal forest test site using thematic mapper data from two dates. Remote Sensing of Environment, 77, 197-211.

Goetz, S.T., Baccini, A., Laporte, N.T., Johns, T., Walker, W., Kellndorfer, J., Houghton, R.A., Sun, M., 2009. Mapping and monitoring carbon stocks with satellite observations: a comparison of methods. Carbon Balance and Management, 4(2), http://dx.doi.org/10.1186/1750-0680-4-2.

Gómez, C. 2006. Estimación de volumen de P. sylvestris L. mediante imágenes Landsat y QuickBird en el Sistema Central español. DEA dissertation. Universidad de Valladolid, Spain, 32 pp.

Gómez, C., Wulder, M.A., Montes, F., Delgado J.A., 2011a. Forest structural diversity characterization in Mediterranean pines of central Spain with QuickBird-2 imagery and canonical correlation analysis. Canadian Journal of Remote Sensing, 37(6), 628-642.

Gómez, C., White, J.C., Wulder, M.A., 2011b. Characterizing the state and processes of change in a dynamic forest environment using hierarchical spatio-temporal segmentation. Remote Sensing of Environment, 115, 1665-1679.

Gómez, C., Wulder, M.A., White, J.C., Montes, F., Delgado J.A., 2012. Characterizing 25 years of change in the area, distribution, and carbon stock of Mediterranean pines in Central Spain. International Journal of Remote Sensing, 33(17), 5546-5573. 
González-Alonso, F., Merino de Miguel, S., Roldán-Zamarrón, A., García-Gigorro, S., Cuevas, J.M., 2006. Forest biomass estimation through NDVI composites. The role of remote sensed data to assess Spanish forests as carbon sinks. International Journal of Remote Sensing, 27, 5409-5415.

Goodwin, N.R., Magnussen, S., Coops, N.C., Wulder, M.A., 2010. Curve fitting of time series Landsat imagery for characterising a mountain pine beetle infestation disturbance. International Journal of Remote Sensing, 31(12) 3263-3271.

Healey, S.P., Yang, Z., Cohen, W.B., Pierce, D.J., 2006. Application of two regression-based methods to estimate the effects of partial harvest on forest structure using Landsat data. Remote Sensing of Environment, 101, 115-126.

Herrero, C., Bravo, F., 2012. Can we get an operational indicator of forest carbon sequestration? A case study from two forest regions in Spain. Ecological Indicators, 17, 120-126

Houghton, R.A., 2005. Aboveground forest biomass and the global carbon balance. Global Change Biology, 11, 945-958.

Houghton, R.A., Butman, D., Bunn, A.G., Krankina, O.N., Schlesinger, P., Stone, T.A. 2007. Mapping Russian forest biomass with data from satellites and forest inventories. Environmental Research Letters, 2 045032 (7pp)

Huang, Ch., Goward, S.N., Schleeweis, K., Thomas, N., Masek, J.G., Zhu, Z. 2009. Dynamics of national forests assessed using the Landsat record: Case studies in eastern United States. Remote Sensing of Environmen, 113, 1430-1442.

Jin, Y.Q., Liu, C., 1997. Biomass retrieval from high-dimensional active/passive remote sensing data by using artificial neural networks. International Journal of Remote Sensing, 18(4), 971-979.

Jin, S., Sader, S.A., 2005. Comparison of time series tasseled cap wetness and the normalized difference moisture index in detecting forest disturbances. Remote Sensing of Environment, 94, 364-372.

Kangas, A., Maltamo, M., 2006. Managing Forest Ecosystems: Forest Inventory: Methodology and Applications. Springer. Dordrecht, Netherlands.

Keith, H., Mackey, B.G., Lindenmayer, D.B. 2009. Re-evaluation of forest biomass carbon stocks and lessons from the world's most carbon-dense forests. Proceedings of the National Academy of Sciences of the United States, 106(28), 11635-11640.

Kennedy, R., Yang, Z., Cohen, W.B., 2010. Detecting trends in forest disturbance and recovery using yearly Landsat time series: 1. LandTrendr - Temporal segmentation algorithms. Remote Sensing of Environment, 114, 2897-2910.

Kollmann, F., 1959. Tecnología de la madera y sus aplicaciones. Translation of second edition. In: German of 'Tecnologie des Holzes und der Holzwerkstoffe: mit 1194 Abbildungen im Text und 6 Tafeln’. Springer, Berlín, Germany. 
Krankina, O.N., Harmon, M.E., Cohen, W.B., Oetter, D.R., Zyrina, O., Duane, M.V. 2004. Carbon stores, sinks, and sources in forests of Northwestern Russia: can we reconcile forest inventories with remote sensing results?. Climatic Change, 67, 257-272.

Kurz, W.A., Apps, M.J., 2006. Developing Canada’s national forest carbon monitoring, accounting and reporting system to meet the reporting requirements of the Kyoto Protocol, Mitigation and Adaptation Strategies for Global Change, 11, 33-43

Kwak, D.A., Lee, W.K., Cho, H.K., Lee, S.H., Son, Y., Kafatos, M., Kim, S.R., 2010. Estimating stem volume and biomass of Pinus koraiensis using LiDAR data. Journal of Plant Research, 123, 421-432.

Labrecque, S., Fournier, R.A., Luther, J.E., Piercey, D., 2006. A comparison of four methods to map biomass from Landsat-TM and inventory data in western Newfoundland. Forest Ecology and Management, 226, 129-144.

Lefsky, M., Cohen, W.B., Spies, T.A., 2001. An evaluation of alternate remote sensing products for forest inventory, monitoring, and mapping of Douglas-fir forests in western Oregon. Canadian Journal of Forest Research 31, 78-87.

Lewis, S.L., Phillips, O.L., Baker, T.R., Lloyds, J., Malhi, Y., Almeida, S., Higuchi, N., Laurance, W.F., Neill, D.A., Silva, J.N.M., Terborgh, J., Torres Lezama, A., Vásquez Martínez, R., Brown, S., Chave, J., Kuebler, C., Nuñez Vargas, P., Vinceti, B., 2004. Concerted changes in tropical forest structure and dynamics: evidence from 50 South American long-term plots. Philosophical Transactions of the Royal Society B, 359, 421-436.

Li, J., 2004. Wavelet-Based Feature Extraction for Improved Endmember Abundance Estimation in Linear Unmixing of Hyperspectral Signals. IEEE Transactions on Geoscience and Remote Sensing, 42(3), 644-649.

Lindsay, R.W., Percival, D.B., Rothrock, D.A., 1996. The discrete wavelet transform and the scale analysis of the surface properties of sea ice. IEEE Transactions on Geoscience and Remote Sensing, 34(3), 771-787.

Liski, J., Karjalainen, T., Pussinen, A., Nabuurs, G.J., Kauppi, P., 2000. Trees as carbon sinks and sources in the European Union. Environmental Science and Policy, 3, 91-97.

Liu, W., Song, C., Schroeder, T.A., Cohen, W.B., 2008. Predicting forest successional stages using multitemporal Landsat imagery with forest inventory and analysis data. International Journal of Remote Sensing, 29(13) 3855-3872.

Lu, D., Mause, P., Brondizios, E., Moran, E., 2004. Change detection techniques. International Journal of Remote Sensing, 25, 2365-2407.

Lu, D., 2005. Aboveground biomass estimation using Landsat TM data in the Brazilian Amazon. International Journal of Remote Sensing, 26(12) 2509-2525. 
Lu, D., Batistella, M., Moran, E., 2005. Satellite estimation of aboveground biomass and impacts of forest stand structure. Photogrammetric Engineering and Remote Sensing, 71(8), 967-974.

Lu, D., 2006. The potential and challenge of remote sensing-based biomass estimation. International Journal of Remote Sensing, 27, 1297-1328.

Lu, D., Chen, Q., Wang, G., Moran, E., Batistella, M., Zhang, M., Laurin, G.V., Saah, D., 2012. Aboveground Forest Biomass Estimation with Landsat and LiDAR Data and Uncertainty Analysis of the Estimates. International Journal of Forestry Research vol 2012, Article ID 436537, 16 pages, doi:10.1155/2012/436537

Mallat, S., Hwang, W.L., 1992. Singularity detection and processing with wavelets. IEEE Transactions on Information Theory, 38(2), 617-643.

Maselli, F., Chirici, G., Bottai, L., Corona, P., Marchetti, M., 2005. Estimation of Mediterranean forest attributes by the application of k-NN procedures to multitemporal Landsat ETM+ images. International Journal of Remote Sensing, 26(17), 3781-3796.

Martínez, B., Gilabert, M.A., 2009. Vegetation dynamics from NDVI time series analysis using the wavelet transform. Remote Sensing of the Environment, 113, 1823-1842.

Meyers, S.D., Kelly, B.G., O’Brien, J.J., 1993. An introduction to wavelet analysis in oceanography and meteorology: with application to the dispersion of Yanai waves. American Meteorological Society, 121, 2858-2866.

Mitchard, E. T. A., Saatchi, S. S., Woodhouse, I. H., Nangendo, G., Ribeiro, N. S., Williams, M., Ryan, M., Lewis, S.L., Feldpausch, T.R., Meir, P. 2009. Using satellite radar backscatter to predict aboveground woody biomass: A consistent relationship across four different African landscapes. Geophysical Research Letters, 36, L23401, doi:10.1029/2009GL040692

Montero, G. Muñoz, M., Donés, J., Rojo, A., 2004. Fijación de CO2 por Pinus sylvestris L. y Quercus pyrenaica Willd. en los montes "Pinar de Valsaín” y "Matas de Valsaín”. Sistemas y Recursos Forestales, 13(2), 399-415.

Montero, G., Ruiz-Peinado, R., Muñoz, M., 2005. Producción de biomasa y fijación de CO2 por parte de los bosques españoles. Monografías INIA: Serie Forestal nº 13, Madrid, 270 pp.

Mutanga, O., Adam, E., Cho, M.Z., 2012. High density biomass estimation for wetland vegetation using WorldView-2 imagery and random forest regression algorithm. International Journal of Applied Earth Observation and Geoinformation 18, 399-406.

Muukkonen, P., Heiskanen J., 2007. Biomass estimation over a large area based on standwise forest inventory data and ASTER and MODIS satellite data: a possibility to verify carbon inventories. Remote Sensing of Environment, 107, 617-624.

Næsset, E., Gobakken, T., 2008. Estimation of above- and below-ground biomass across regions of the boreal forest zone using airborne laser. Remote Sensing of Environment, 112, 3079-3090. 
Niedermeier, A., Romaneeben, E., Lehner, S., 2000. Detection of coastlines in SAR images using wavelet methods, IEEE Transactions on Geoscience and Remote Sensing, 38(5) 2270-2281.

Penman, J., Gytarsky, M., Hiraishi, T., Krug, T., Kruger, D., Pipatti, R., Buendia, L., Miwa, K., Ngara, T., Tanabe, K., Wagner, F., 2003. Good Practice Guidance for Land Use, Land-Use Change and Forestry. Intergovernmental Panel on Climate Change (IPCC), Hayama, Japan.

Percival, D.B., Wang, M., Overland, J.E., 2004. An introduction to wavelet analysis with applications to vegetation time series. Community Ecology, 5(1), 19-30.

Peterson, U., Nilson, T., 1993. Successional reflectance trajectories in northern temperate forests. International Journal of Remote Sensing, 14, 609-613.

Piao, Sh., Fang, J., Zhu, B., Tan, K., 2005. Forest biomass carbon stocks in China over the past 2 decades: Estimation based on integrated inventory and satellite data. Journal of Geophysical Research, 110, G01006, doi:10.1029/2005JG000014

Pflugmacher, D., Cohen, W.B., Kennedy, R.E., 2012. Using Landsat-derived disturbance history (19722010) to predict current forest structure. Remote Sensing of Environment, 122, 146-165.

Powell, S.L., Cohen, W.B., Healey, S.P., Kennedy, R.E., Moisen, G.G, Pierce, K.B., Ohmann, J.L., 2010. Quantification of live aboveground biomass dynamics with Landsat time-series and field inventory data: A comparison of empirical modeling approaches. Remote Sensing of Environment, 114, 1053-1068.

Rahman, M.M., Csaplovics, E., Koch, B., 2005. An efficient regression strategy for extracting forest biomass information from satellite sensor data. International Journal of Remote Sensing, 26 (7), 15111519.

Raja, R.A.A., Anand, V., Kumar, A.S., Maithani, S., Kumar, V.A., 2013. Wavelet Based Post Classification Change Detection Technique for Urban Growth Monitoring. Journal of Indian Society Remote Sensing, 41(1), 35-43.

Ratanamahatana, Ch.A., Keogh, E., 2005. Three myths about Dynamic Time Warping data mining. SIAM International Conference on Data Mining (SDM), Newport Beach, California, April 21-23.

Rivas-Martínez, S., 1963. Estudio de la vegetación y flora de la Sierra de Guadarrama y Gredos. Anales del Instituto Botánico A.J. Cavanilles, 21, 5-325.

Ruiz-Peinado R., Río M., Montero G., 2011. New models for estimating the carbon sink capacity of Spanish softwood species. Forest Systems, 20 (1), 176-188.

Saatchi, S.S., Houghton, R.A., Dos Santos Alvala, R.C., Soares, J.V., Yu, Y., 2007. Distribution of aboveground live biomass in the Amazon basin. Global Change Biology, 13, 816-837.

Salvador, R., Pons, X., 1998. On the applicability of Landsat TM images to Mediterranean forest inventories. Forest Ecology and Management, 104, 193-208. 
Sakamoto, T., Yokozawa, M., Toritani, H., Shibayama, M., Ishitsuka, N., Ohno, H., 2005. A phenology detection method using time-series MODIS data. Remote Sensing of Environment, 96, 366-374.

Schroeder, T.A., Cohen, W.B., Yang, Z., 2007. Patterns of forest regrowth following clearcutting in western Oregon as determined from a Landsat time-series. Forest Ecology and Management, 243, 259-273.

Serrada, R. 2008. Apuntes de selvicultura. Servicio de publicaciones. EUIT Forestal. Madrid.

Simhadri, K.K., Iyengar, S.S., Holyer, R.J., Lybanon, M., Zachary, J.M., 1998. Wavelet-based feature extraction from oceanographic images. IEEE Transactions on Geoscience and Remote Sensing, 36(3), 767-778.

Smeets, E.M.W., Faaij, A.P.C., 2007. Bioenergy potentials from forestry in 2050. Climatic Change, 81(3), 353-390.

Song, C., Woodcock, C.E., Li, X., 2002. The spectral/temporal manifestation of forest succession in optical imagery: the potential of multitemporal imagery. Remote Sensing of Environment, 82, 285-302.

Song, C., Schroeder, T.A., Cohen, W.B., 2007. Predicting temperate conifer forest successional stage distributions with multitemporal Landsat Thematic Mapper imagery. Remote Sensing of Environment, 106, 228-237.

Sun, G., Ranson, K.J., Guo, Z., Zhang, Z., Montesano, P., Kimes, D., 2011. Forest biomass mapping from lidar and radar synergies. Remote Sensing of Environment, 115, 2906-2916.

Tan, K., Piao, S., Peng, C., Fang, J., 2007. Satellite-based estimation of biomass carbon stocks for northeast China’s forests between 1982 and 1999. Forest Ecology and Management, 240, 114-121.

Turner, D.P., Cohen, W.B., Kennedy, R.E., Fassnacht, K.S., Briggs, J.M., 1999. Relationship between leaf area index and Landsat TM spectral vegetation indices across three temperate zone sites. Remote Sensing of Environment, 70, 52-68.

Vázquez de la Cueva, A., 2008. Structural attributes of three forest types in central Spain and Landsat ETM+ information evaluated with redundancy analysis. International Journal of Remote Sensing, 29 (19), 5657-5676.

Velichko, V.M., Zagoruyko, N.G., 1970. Automatic recognition of 200 words. International Journal of Man-Machine Studies, 2, 223-234.

Vicente-Serrano, S.M., Perez-Cabello, F., Lasanta, T., 2008. Assessment of radiometric correction techniques in analyzing vegetation variability and change using time series of Landsat images. Remote Sensing of Environment, 112, 3916-3934.

Wang, G., Oyana, T., Zhang, M., Adu-Prah, S., Zeng, S., Lin, H., Se, J., 2009. Mapping and spatial uncertainty analysis of forest vegetation carbon by combining national forest inventory data and satellite images. Forest Ecology and Management, 258, 1275-1283. 
Wulder, M.A., White, J.C., Fournier, R.A., Luther, J.E., Magnussen, S., 2008. Spatially explicit large area biomass estimation: three approaches using forest inventory and remotely sensed imagery and GIS. Sensors, 8, 529-560.

Wulder, M. A., Masek, J. G., Cohen, W. B., Loveland, T. R., Woodcock, C. E., 2012. Opening the archive: How free data has enabled the science and monitoring promise of Landsat. Remote Sensing of Environment, 122, 2-10.

Yu, Y., Saatchi, S., Heath, L.S., LaPoint, E., Myneni, R., Knyazikhin, Y., 2010. Regional distribution of forest height and biomass from multisensor data fusion, Journal of Geophysical Research, 115, G00E12, doi:10.1029/2009JG000995.

Zhou, J., Civco, D.L., Silander, J.A., 1998. A wavelet transform method to merge Landsat TM and SPOT panchromatic data. International Journal of Remote Sensing, 19(4), 743-757.

Zhu, Z., Woodcock, C.E., Olofsson, P., 2012. Continuous monitoring of forest disturbance using all available Landsat images. Remote Sensing of Environment, 122, 75-91. 